\title{
Scratch formation and its mechanism in chemical mechanical planarization (CMP)
}

\author{
Tae-Young KWON, Manivannan RAMACHANDRAN, Jin-Goo PARK* \\ Department of Materials Engineering, Hanyang University, Ansan 426-791, Korea \\ Received: 14 June 2013 / Revised: 09 August 2013 / Accepted: 01 September 2013 \\ (C) The author(s) 2013. This article is published with open access at Springerlink.com
}

\begin{abstract}
Chemical mechanical planarization (CMP) has become one of the most critical processes in semiconductor device fabrication to achieve global planarization. To achieve an efficient global planarization for device node dimensions of less than $32 \mathrm{~nm}$, a comprehensive understanding of the physical, chemical, and tribo-mechanical/chemical action at the interface between the pad and wafer in the presence of a slurry medium is essential. During the CMP process, some issues such as film delamination, scratching, dishing, erosion, and corrosion can generate defects which can adversely affect the yield and reliability. In this article, an overview of material removal mechanism of CMP process, investigation of the scratch formation behavior based on polishing process conditions and consumables, scratch formation mechanism and the scratch inspection tools were extensively reviewed. The advantages of adopting the filtration unit and the jet spraying of water to reduce the scratch formation have been reviewed. The current research trends in the scratch formation, based on modeling perspective were also discussed.
\end{abstract}

Keywords: Chemical mechanical planarization (CMP); defects, scratch; post-CMP cleaning; defect source

\section{Introduction}

Recent advances in integrated circuit (IC) technology have led to a significant increase in the number of the active components with a significant decrease in feature dimensions. This has resulted in the development of high performance IC chips. As the critical features of semiconductor devices have decreased to nanoscale dimensions and additional levels are implemented leading to multilevel-interconnection, the required degree of planarization has become more challenging. Moreover, continuous improvement is required for smaller technology nodes. As the device feature size decreases, it becomes very challenging to achieve high resolution on a non-planarized surface using lithography because of the depth of focus requirement in optical systems. Rough and irregular surfaces induce variation in the photo resist thickness, which results

* Corresponding author: Jin-Goo PARK.

E-mail: jgpark@hanyang.ac.kr in poor step coverage and contact interruption. In order to improve the planarity, various planarization techniques were considered, such as thermal reflow of borophosphosilicate glass (BPSG), reactive ion-etch back, spin etch planarization, spin on deposition (SOD) and others [1]. However, these techniques are extremely limited in achieving a global planarization suitable for submicron devices. On the other hand, chemical mechanical planarization (CMP) is a unique technique that can provide excellent local and global planarity for ultra large scale integrated (ULSI) applications. Figure 1 shows the planarization length of various methods used for removing the excess material. Initially, the CMP process was pioneered by IBM in 1980s [3, 4]. The CMP process became prominent due to advantages such as global planarization, fewer defects, better step coverage, suitable for various materials, and simplicity $[1,5]$. The advantages of CMP are tabulated in Table 1. CMP has been developed for dielectric planarization applications. CMP is also used to remove bulk dielectric films on the surface to isolate 


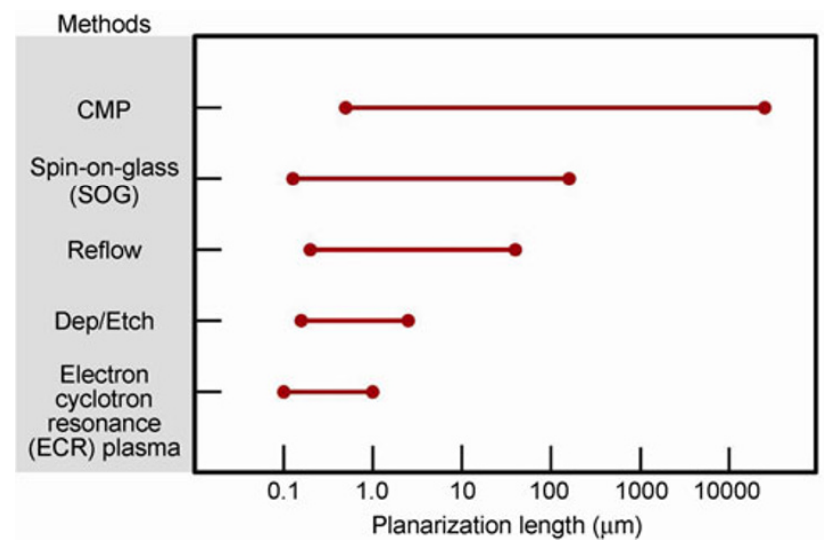

Fig. 1 Planarization lengths of various planarization methods [2].

the active devices on silicon substrates and to remove the bulk metal films from the wafer surface to form metal interconnection plugs or lines in dielectric films $[2,6]$. Due to an increase in the number of transistors on IC chips of dynamic random access memory (DRAM) and logic devices, new interconnect materials are essential to satisfy the higher performance requirements.

$\mathrm{CMP}$ is a global planarization process in which the wafer surface is planarized using the synergistic effect of chemical and mechanical actions. During the CMP process, the wafer surface moves across a polishing pad under a down pressure in the presence of a slurry. There are many consumables for the CMP process, such as the slurry, polishing pad, and diamond conditioners $[3,5,7,8]$. CMP involves a complex interaction between the wafer surface and the consumables. Figure 2 shows a schematic diagram of the CMP process and highlights the consumables. The type of slurry to be used depends on the material surface, which, in turn, is related to the chemical and mechanical properties of wafer material.

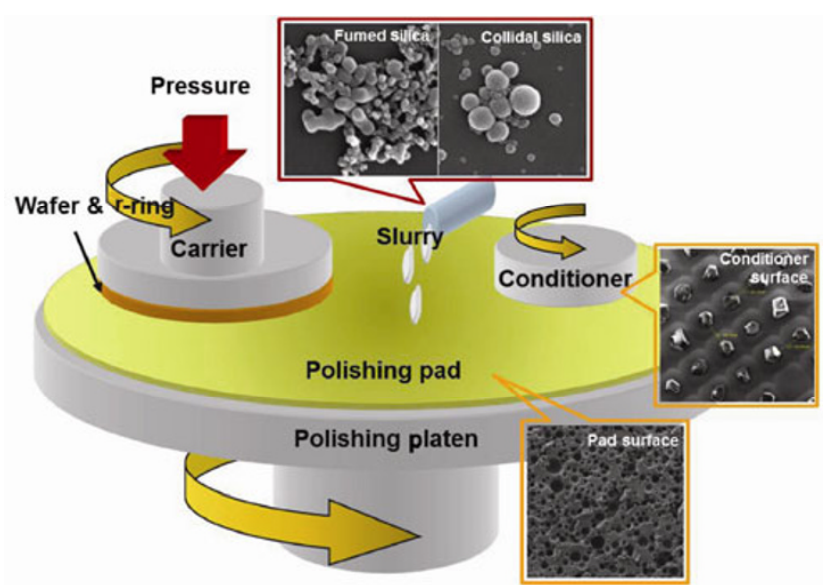

Fig. 2 Schematic diagram and consumables of CMP process.

Silica and ceria are the most commonly used abrasives particles. The abrasive particles used are in the nanometer range. The nature of the abrasive particles and their size distribution plays an important role in material removal during the CMP process $[9,10]$. Additives added to the slurry play different roles during oxide and metal CMP. In general, metal CMP slurry contains more chemical additives when compared to an oxide CMP slurry. A metal CMP slurry contains oxidizing agents, complexing agents, corrosion inhibitors, dispersion agents, and $\mathrm{pH}$ adjustors. The CMP slurry is delivered to the polishing pad using a pump. A rotating polishing pad transports the slurry to the wafer surface [11]. Contact area is provided between the abrasive-pad and the abrasive-wafer interfaces $[12,13]$. The structure of the polishing pad and its properties are important in determining the removal rate and planarization efficiency [7]. The polishing pad has numerous micro pores and grooves

Table 1 Advantages of the CMP process (Reproduced from Ref. [1], with permission from Elsevier).

\begin{tabular}{ll}
\hline \multicolumn{1}{c}{ Advantages } & \multicolumn{1}{c}{ Remarks } \\
\hline Planarization & Achieves global planarization \\
Planarize different materials & Wide range of wafer surfaces can be planarized \\
Planarize multimaterial surfaces & Useful for planarizing multiple materials during the same polishing step \\
Reduce severe topography & $\begin{array}{l}\text { Reduces severe topography to allow fabrication with tighter design rules and additional } \\
\text { interconnection levels }\end{array}$ \\
Alternative method of metal patterning & $\begin{array}{l}\text { Provides an alternate means of patterning metal, eliminating the need to plasma etch, } \\
\text { difficult to etch metals and alloys }\end{array}$ \\
Improved metal step coverage & $\begin{array}{l}\text { Improves metal step coverage due to reduction in topography } \\
\text { Increased IC reliability }\end{array}$ \\
Reduced defects & Contributes to increasing IC reliability, speed, yield (lower defect density) \\
No hazardous gases & Does not use hazardous gas, which is common in dry etch process \\
\hline
\end{tabular}


for delivery of the slurry [14]. Hence, the mechanisms for CMP are lubrication behavior and abrasion, such as direct contact between the wafer and polishing pad (two body abrasion) and contact between the wafer, the pad, and the abrasive in the presence of a slurry film occurring in the asperity region (three body abrasion) [14]. The role of the diamond conditioner is to excise the pad surface in order to maintain its roughness against the plastic deformation and to prevent glazing due to the accumulation of polishing residues in the pad pores $[8,15,16]$. This review article is divided into the following sections: Section 2, modeling of CMP; Section 3, scratch issues in CMP process; Section 4, scratch inspection tools; Section 5, scratch formation source; and Section 6, scratch formation mechanism. This review focuses on the latest developments and current status of research on CMP scratches and possible solution to avoid the scratches and outline the scopes for future research.

\section{Modeling of chemical mechanical planarization}

The mechanism of CMP based on the mechanical interactions between the wafer, pad, and abrasive particle has been studied by several groups. The most fundamental and basic material removal model in CMP is the Preston model, which is applicable for glass polishing [17]. This equation states that the material removal rate (MRR) is directly proportional to the pressure and relative velocity as follows:

$$
\mathrm{MRR}=K_{\mathrm{p}} \cdot P \cdot V
$$

where MRR is the material removal rate in $\mathrm{m} / \mathrm{min}, P$ is the down pressure in $\mathrm{N} / \mathrm{m}^{2}, V$ is the relative velocity between the pad and wafer in $\mathrm{m} / \mathrm{min}$ and $K_{\mathrm{p}}$ is the Preston coefficient in $\mathrm{m}^{2} / \mathrm{N}$. The Preston coefficient depends on various factors that can affect the removal rate such as friction force, chemical reaction, heating and so on. This is an empirical equation for understanding mechanical action during the CMP process, which shows the linear dependency.

However, MRR is not zero for some materials, even when $P$ and $V$ are zero. Such behavior is most commonly seen in metal CMP. Hence, a modified Preston's equation was proposed based on the Cu CMP [18].
Removal rate has a non-zero intercept at both zero velocity and pressure and has a greater dependence on the velocity compared to the pressure. Thus, Luo et al. [18] proposed a modified Preston equation as follows:

$$
\begin{aligned}
\mathrm{MRR} & =K\left(P+P_{0}\right)\left(V+V_{0}\right) \text { or MRR } \\
& =K P V+a P+b V+R_{\mathrm{c}}
\end{aligned}
$$

where, $P_{0}, V_{0}, a, b$, and $R_{c}$ are constants. However, Eq. (2) predicts that the removal rate increases with the pressure even at zero velocity, which was not consistent with their experimental data.

The final, modified form of the equation, according to Luo et al. [18] is given as follows

$$
\mathrm{MRR}=(K P+B) V+R_{\mathrm{c}}
$$

where $K, B$, and $R_{\mathrm{c}}$ are constants and were obtained by a least squares procedure. The Preston coefficient and other constants can be obtained from experimental data.

Cook [19] developed a MRR model based on Hertzian elastic penetration of a spherical particle with pressure in which the interaction between the abrasive particle and wafer surface occurs. Also, Liu et al. [20] proposed a model which is based on a statistical method and elastic theory to describe the MRR mechanism of silicon wafer surface during the CMP process. In this model, the parameters of removal rate are hardness of wafer film and pad, and Young's modulus of abrasive and film material. The advantage of Cook's and Liu's MRR model, based on Hertzian contact, is the importance given to the role and interactions of the consumable.

Runnels [21] proposed a model by considering the slurry fluid film. The importance of wafer curvature, slurry viscosity, and thickness of the fluid film was described in the model. The stresses induced by the flowing slurry on feature surfaces were computed and used in erosion models that empirically incorporated the fracture mechanics and chemistry. Tseng and Wang [22] proposed a MRR model for the CMP process through the combination of solid and fluid mechanics. This model is given by $\mathrm{MRR}=M P^{5 / 6} V^{1 / 2}$, where $M$ is a constant associated with material properties such as abrasive concentration and chemical processes during CMP. Also, this model was obtained using a non-linear relationship between the material 
removal and relative velocity. This might be due to the contribution of velocity to the slurry flow instead of a sliding of abrasives. Zhang et al. [23] proposed an equation $\mathrm{MRR}=K(P V)^{1 / 2}$ which included the effects of polishing pressure and platen speed on particle penetration depth in the CMP process. This equation was derived based on the surface plastic deformation, the pad-wafer partial contact, and particle adhesion theory. Abrasive particle-surface interactions were analyzed and material removal by adhesive and abrasive removal mechanisms during CMP process were extensively studied by Ahmadi and Xia [24]. The material removal rate was found to be related to the distribution of pad asperities. A linear dependence was obtained when the pad asperities have a random distribution, while a sub linear dependence was observed when the pad asperities have a wavy distribution.

During the CMP process, the removal rate was affected by the pad surface properties. For example, MRR increases with the pad surface roughness [25]. $\mathrm{Yu}$ et al. [26] considered the effect of pad surface roughness and the interaction between the pad and wafer with the contact area. Their results showed that the real pressure is induced by the contact area, and moderately depends on the applied pressure. Also, the ratio of real contact area was smaller than the nominal contact area and is proportional to the down pressure. The physical CMP model, which includes the effects of polishing pad roughness and dynamic interaction between the pad and wafer, is based on the asperity theory. Zhao and Shi [27] also proposed a model based on wafer-asperity contact. The polishing pressure dependence of MRR for the CMP with a soft pad was found to be sub-linear. Also, abrasive particles can demonstrate a threshold pressure during CMP processes, which might have played a critical role in MRR. Furthermore, the contact area between the asperity and the wafer is given by $A \propto P^{2 / 3}$ based on Hertzian elastic contact theory. Finally, the modified MRR equation is given as MRR $=K(V)\left(P^{2 / 3}-P_{\mathrm{th}}^{2 / 3}\right)$ at $P \geqslant P_{\mathrm{th}}$, and $\mathrm{MRR}=0$ at $P<P_{\text {th }}$, where $P_{\text {th }}$ is the threshold pressure, and $K(V)$ is a function of relative velocity $(V)$ and other CMP parameters. Figure 3 shows a schematic diagram showing the polishing mechanism and the criterion for material removal. When the abrasive

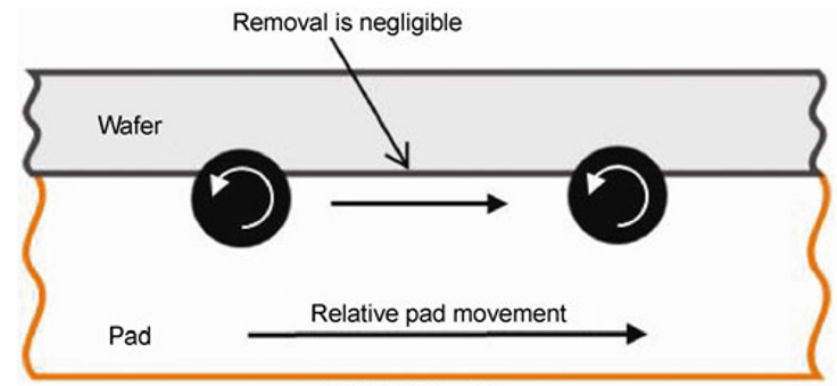

(a) Particle rolling

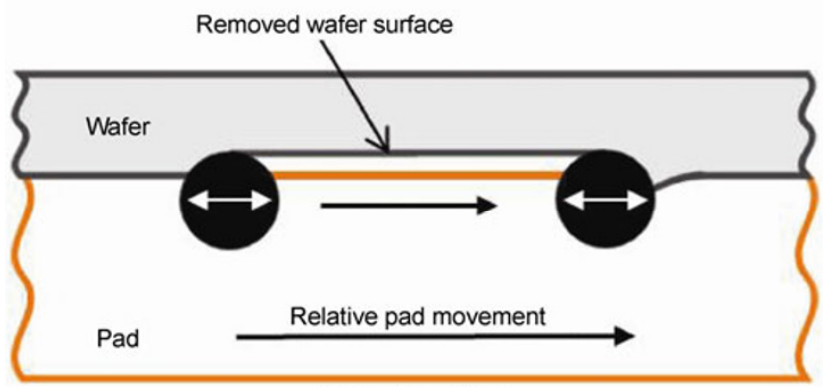

(b) Particle sliding

Fig. 3 Schematic diagram showing the polishing mechanism and the criterion for material removal [27].

particles are rolling against the wafer surface under a pressure lower than the threshold value, the removal rate will be negligible. The removal rate was found to be significant only if the abrasive particles held by the pad were sliding against the wafer surface. In other words, removal rate was found to be negligible, if the applied pressure is less than the minimum threshold pressure.

Luo and Dornfeld [28] investigated the abrasion mechanism in solid-solid contact mode of the CMP process based on the assumptions of plastic contact over wafer-abrasive and pad-abrasive interfaces. Figure 4 shows the two contact modes of the CMP process: the hydro-dynamical contact mode and the solid-solid contact mode. The Luo and Dornfeld model combined the process parameters including pressure and velocity in addition to other properties such as pad and wafer hardness, pad roughness, abrasive particle size, morphology and its distribution in the same equation to predict the MRR. The material removal rate can be predicted by MRR $=\rho_{\mathrm{w}} N \mathrm{Vol}_{\text {removed }}+C_{0}$, where $\rho_{\mathrm{w}}$ is the density of wafer material, $N$ is the number of active abrasive particles, $\mathrm{Vol}_{\text {removed }}$ is the volume of material removed by a single abrasive per unit time, and $C_{0}$ is the material removal due to chemical etching. Also, they suggest that two-body abrasion between 


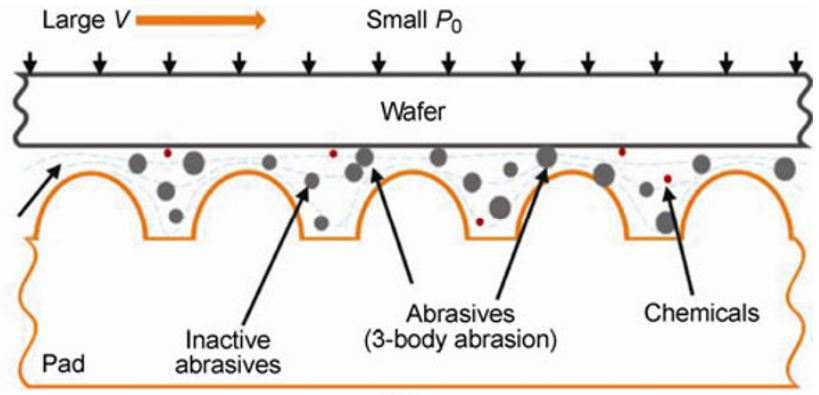

(a)

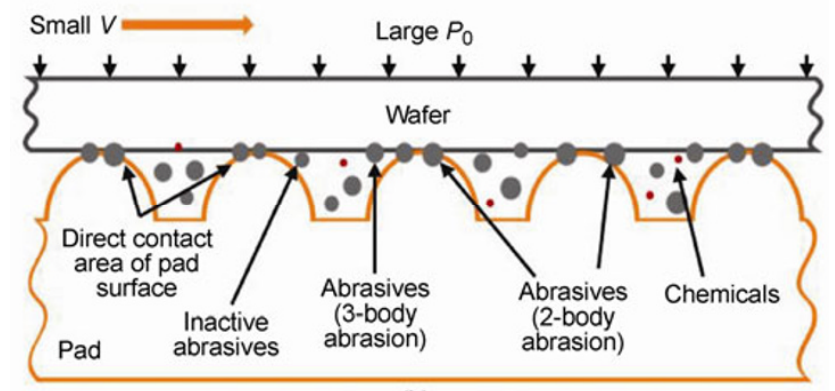

(b)

Fig. 4 Two contact modes of CMP: (a) hydro-dynamical contact mode and (b) solid-solid contact mode [28].

the wafer and an abrasive particle mainly affects the material removal when compared to three body abrasion.

\section{Scratch issues in CMP process}

In the manufacturing of IC chips, the wafer is polished several times using the CMP process. CMP has been applied for polishing various types of surfaces, including oxides, $\mathrm{Cu}, \mathrm{W}$ and others [7]. However, several defects induced by CMP depend on the type of surface being polished. This may be attributed to the effects of various chemicals and abrasive particles as well as the pressure exerted on the wafer surface $[7,29]$. Defects typically formed during the CMP process include organic residues [29], water marks [30], particle adherence and impingement [31], corrosion pit, and scratches [30,31]. However, the removal of organic residues and water mark formation are trivial in oxide CMP, but other types of defects, such as scratch formation, are critical, as they affect the yield and reliability of the devices [32]. Table 2 shows the CMP process induced defects and their specific effects on the replacement metal gate (RMG) process [33].

Scratches are one of the most commonly generated defects during the CMP process. It was found that $\mathrm{CMP}$ scratches could cause an initial failure as well as long term reliability failure [34]. The failure mechanism in the shallow trench isolation (STI), inter-level dielectric (ILD), and poly-Si CMP processes is very similar in nature. Scratches cannot be detected after CMP, but are usually identified after etching using the HF solution [33]. The periodic arc scars generated on brittle materials such as oxide, BPSG, and poly-Si are called chatter mark-type scratches [33,35]. Figure 5 shows some examples of chatter mark scratches after STI CMP. Scratch shape is influenced by the mechanical properties of the material. A wide variety of scratches are formed on a metal surface like $\mathrm{Cu}$, which is shown in Fig. 6.

Surface defects by CMP have been continuously reduced by the development of abrasive particles and slurries, polishing pads, diamond conditioners and

Table 2 Potential causes of CMP defects and possible solutions [33].

\begin{tabular}{|c|c|c|c|}
\hline Defect mode & Potential causes & Impact to device & Potential solutions \\
\hline Particles & $\begin{array}{l}\text { - Slurry/pad residue } \\
\text { - Polish byproducts }\end{array}$ & $\begin{array}{l}\text { - Shorting/opens } \\
\text { - Pattern distortion }\end{array}$ & $\begin{array}{l}\text { - Cleaner tooling } \\
\text { - Clean chemistries }\end{array}$ \\
\hline Macro scratches & $\begin{array}{l}\text { - Large/hard foreign particles } \\
\text { on polish pad }\end{array}$ & - Pattern removal over multiple die & $\begin{array}{l}\text { - Pad conditioning } \\
\text { - Pad cleaning } \\
\text { - Environment }\end{array}$ \\
\hline Micro scratches & $\begin{array}{l}\text { - Slurry agglomeration } \\
\text { - Pad asperities }\end{array}$ & - Shorting/opens & $\begin{array}{l}\text { - Slurry filters } \\
\text { - } \mathrm{Pad} / \text { pad conditioning }\end{array}$ \\
\hline $\begin{array}{l}\text { Corrosion (metal } \\
\text { CMP) }\end{array}$ & $\begin{array}{l}\text { - Slurry chemistry } \\
\text { - Clean chemistry }\end{array}$ & - Opens, Reliability & $\begin{array}{l}\text { - Passivating films, } \\
\text { - Chemistry optimization }\end{array}$ \\
\hline Film delamination & $\begin{array}{l}\text { - Weak adhesion } \\
\text { - CMP shear force }\end{array}$ & $\begin{array}{l}\text { - Shorting/opens } \\
\text { - Device parametrics }\end{array}$ & $\begin{array}{l}\text { - Improve adhesion } \\
\text { - Low pressure CMP }\end{array}$ \\
\hline Organic residue & $\begin{array}{l}\text { - Inadequate cleaning } \\
\text { - Residual slurry components }\end{array}$ & $\begin{array}{l}\text { - Shorting/opens } \\
\text { - Disturbed patterning of next layer }\end{array}$ & $\begin{array}{l}\text { - Cleaner tooling } \\
\text { - Slurry optimization } \\
\text { - Clean chemistries }\end{array}$ \\
\hline
\end{tabular}




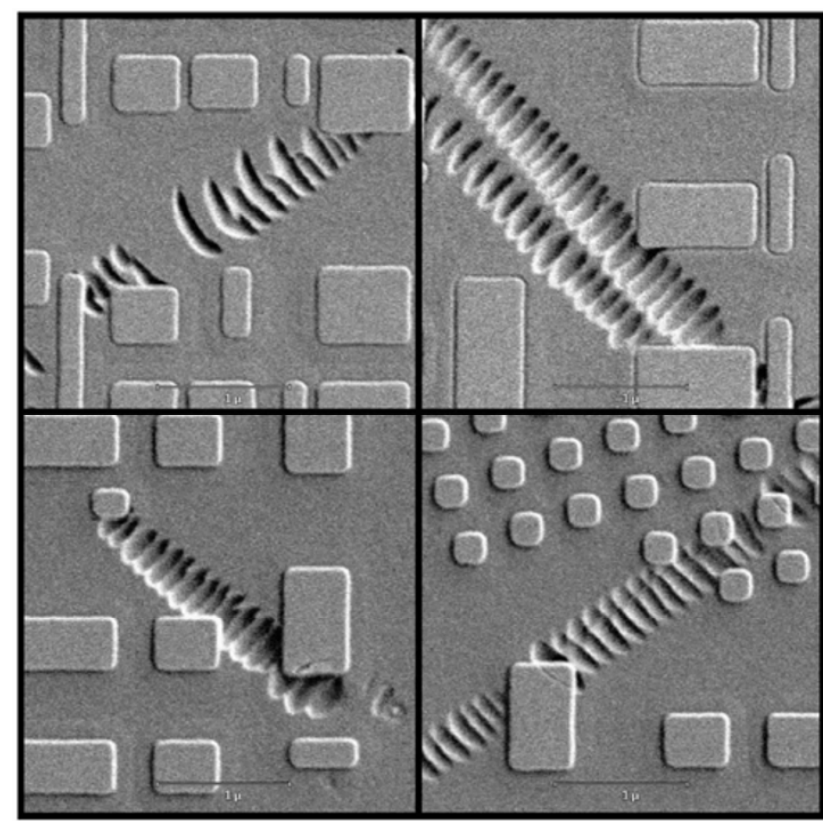

Fig. 5 Chatter mark scratches observed in STI CMP [33].

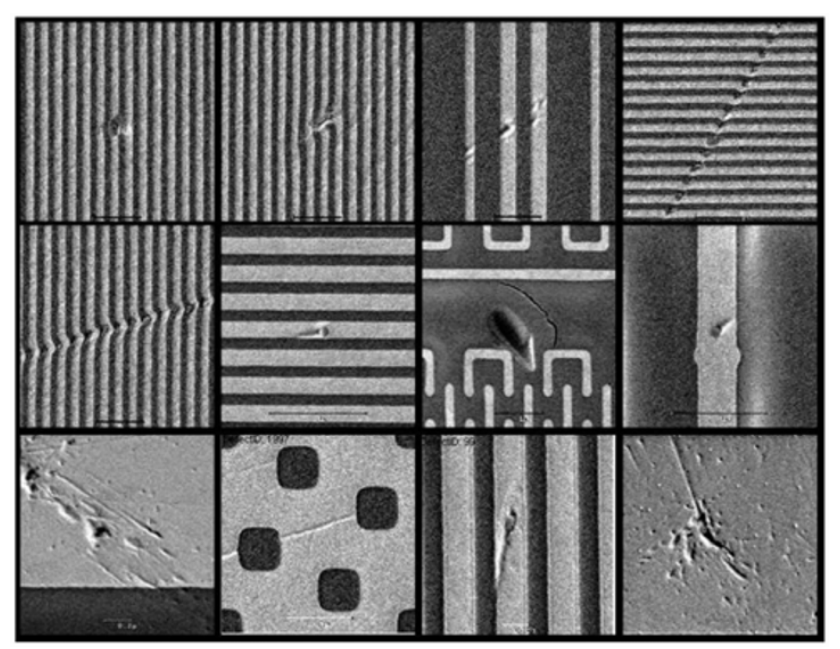

Fig. 6 Various scratches formed in Cu CMP [33]. so on. However, as the scale of integration is reduced, strict control of surface defects, such as scratches, is required according to the International Technology Roadmap for Semiconductors (ITRS) (Table 3) [36].

\section{Scratch inspection tools}

As the application of the CMP process increases, various unpredicted defects occur. However, those defects cannot be easily detected after CMP, and the shape of such scratches depends on the source. Various contaminated particles and defects on the wafers were identified and characterized by means of optical microscope, surface scanning inspection, scanning electron microscopy (SEM), and atomic force microscopy $[37,38]$. In particular, the inspection tools that use the light scattering behavior have been used for monitoring the scratches. Some instruments such as confocal review stations (CRS) [39], advanced inspection tools (ATI) [40], and optical surface analyzers (OSAs) [41] are used in the industry. The optical inspection system usually uses a bright and dark field system. In the case of bright-field systems, both the scattered light and reflected light are collected through the same aperture to obtain an image. However, a dark field system collects selectively the scattered light and not the reflected light within the collection angle [42].

\section{Scratch formation sources}

\subsection{High particle concentration and agglomerated particles}

In the CMP process, several possible reasons for scratch formation have been proposed in the literature [43-74]

Table 3 Critical scratch length and number on ITRS 2010 [36].

\begin{tabular}{|c|c|c|c|c|}
\hline \multicolumn{3}{|c|}{ STI CMP technology requirements } & \multicolumn{2}{|c|}{ Scratches } \\
\hline Year of production & $\begin{array}{l}\text { DRAM 1/2 pitch (nm) } \\
\text { (contacted) }\end{array}$ & Wafer diameter $(\mathrm{mm})$ & $\begin{array}{c}\text { Critical scratch length, } \\
\text { sc }(\mathrm{nm})\end{array}$ & $\begin{array}{c}\text { Critical scratch count, } \\
\text { spw (wafer }{ }^{-1} \text { ) }\end{array}$ \\
\hline 2012 & 36 & 300 & 17.9 & 40.1 \\
\hline 2013 & 32 & 300 & 15.9 & 40.1 \\
\hline 2014 & 28 & 450 & 15.9 & 150.5 \\
\hline 2015 & 25 & 450 & 12.6 & 104.6 \\
\hline 2016 & 22.6 & 450 & 11.3 & 104.6 \\
\hline 2017 & 20.0 & 450 & 10.0 & 104.6 \\
\hline 2018 & 17.9 & 450 & 8.9 & 104.6 \\
\hline
\end{tabular}


and can be broadly classified into process conditions (down pressure, velocity, etc.) based scratches and consumables (slurries include abrasive particles, pads, conditioners, etc) based scratches. CMP consumables can cause surface scratches due to particle agglomeration, release of diamonds from the conditioner, or pad debris. Several reports discussing the effects of these factors on scratch formation have been published [44-74]. Lin et al. [75] evaluated the number of scratches formed during CMP on various film surfaces in the manufacturing of DRAM devices. The micro-scratch number on the SiN cap layer was much lower, which might be due to the higher hardness. Also, they optimized the film thickness of filled oxide and SiN cap layer to reduce micro-scratches, based on the difference in material hardness.

Typically, a CMP process consists of chemical and mechanical interactions between the wafer and polishing pad with a slurry. The mechanical action is attributed to the abrasive particle and polishing pad interactions. Hence, scratches resulting from mechanical polishing are inevitable. The abrasive particle size distribution influences the number and size of the active abrasives [76]. Seo and Kim focused on micro-scratch generation caused by agglomerated particles, which are solidified and attached in the pipeline of a slurry supply system [30, 40, 43]. They evaluated the effect of abrasive particle size distribution and controlled the large particle concentration by installing a point of use (POU) slurry filter. Figure 7 shows a schematic diagram of the CMP tool with a POU filter. Figure 8 shows a comparison of defect densities as a function of number of wafers polished

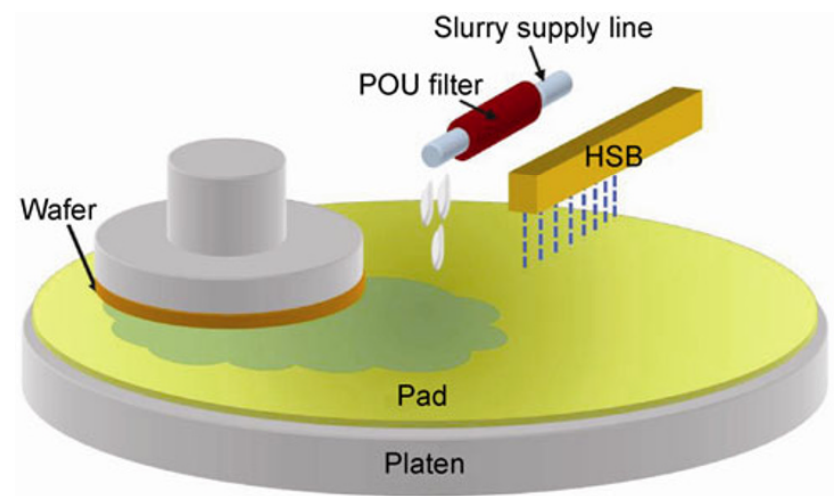

Fig. 7 Schematic diagram of the CMP tool with a POU filter and high pressure spray bar (HSB) of DI water [30]. with a POU filter. Based on their results, the defects were remarkably reduced after installation of the POU filter. Also, they showed that the slurry filter plays an important role in the determination of pad lifetime.

The effect of a high spray bar (HSB) method, i.e., de-ionized water (DIW) with high pressure during CMP was evaluated. High spray bar can prevent the accumulation of large particles on the pad. As a result, the defect density was significantly reduced when compared with an un-installed high spray method. Figure 9 [43] shows the defect density trend obtained with and without a high pressure DI water spray bar during CMP.

Teo et al. [44] characterized the scratches generated during $\mathrm{Cu} C \mathrm{CMP}$ as a function of process pressure and velocity with different abrasive particles. In their results, scratches generated on the $\mathrm{Cu}$ surface were classified into two types, long scratches and triangular scratches. A likely cause for a long scratch is that abrasive particles become embedded in the polishing pad during the polishing process. On the other hand, a possible cause for triangle scratches could be due to freely suspended abrasive particles being driven onto the Cu surface. Also, it was found that deeper scratches were detected when larger and harder abrasive particles, like alumina particles, were used for $\mathrm{Cu} C \mathrm{CMP}$.

Also, it was noted that the occurrence of scratches can increase due to the agglomeration of the abrasive particles. Flushing the stagnant slurry in the slurry pipe line might remove the agglomerated abrasive particles. For example, the flushing procedure effectively reduced scratch generation (Fig. 10).

Ahn et al. [45] evaluated the surface roughness of $\mathrm{Al}$ after CMP performed using the optimum conditions of a silica based slurry and compared these with the conventional alumina based slurry. The agglomeration of particles induced by zeta-potential and oxide layer thickness of $\mathrm{Al}$, which are a function of $\mathrm{pH}$, could also affect the surface roughness. Also, the surface roughness of $\mathrm{Al}$ increased with an increase in abrasive concentration. The reason for this seems to be that friction was more severe at high abrasive concentrations. Kim et al. [46] focused on controlling the agglomeration of ceria particles using the organic additives and $\mathrm{pH}$ adjusters to reduce micro-scratches. Remsen et al. [47] used a dual-sensor single particle optical sensing (SPOS) 


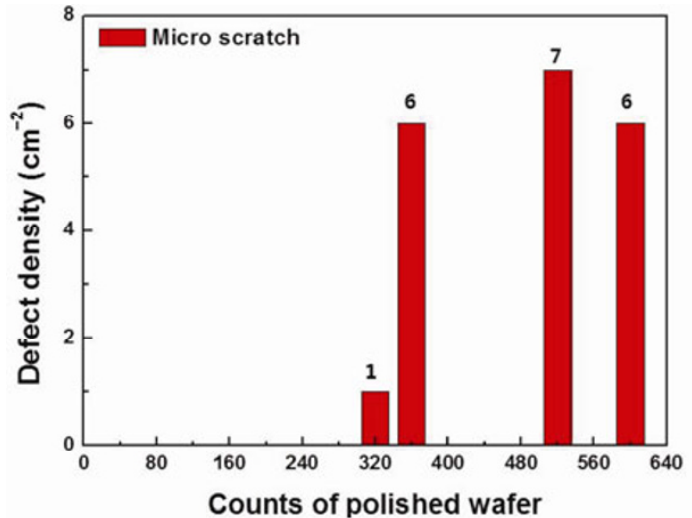

(a)

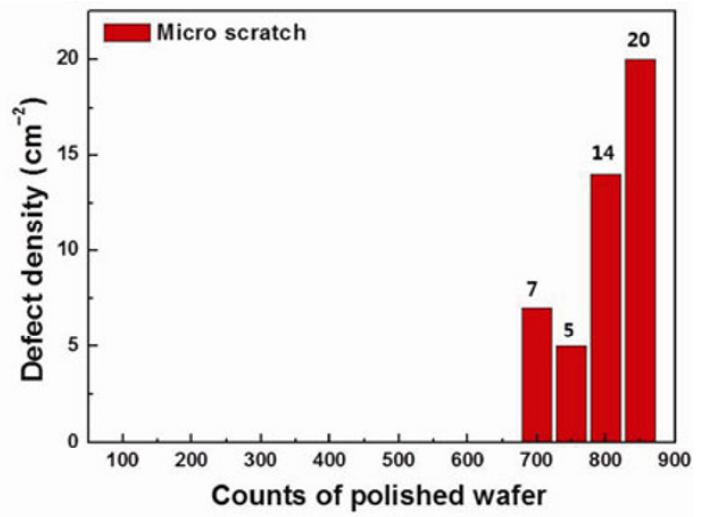

(b)

Fig. 8 Defect density as a function of polished wafer counts (a) without filter and (b) with $0.5 \mu \mathrm{m}$ filter [30].

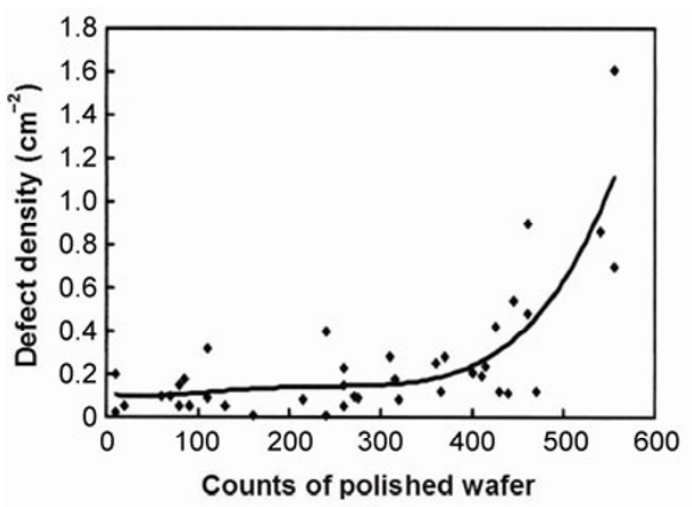

(a)

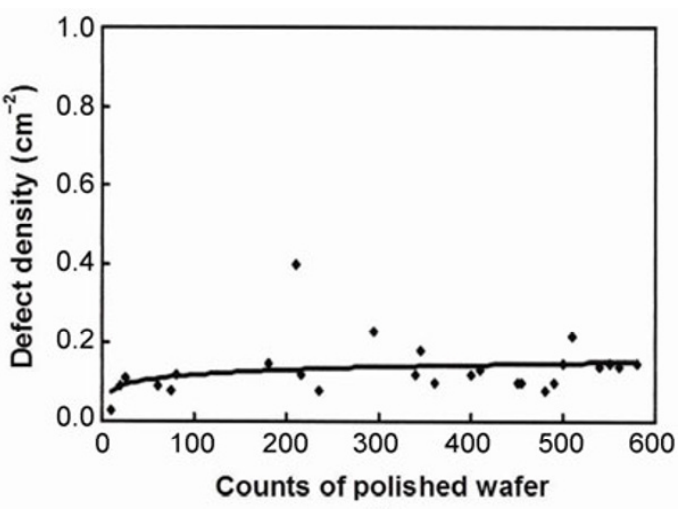

(b)

Fig. 9 Defect density trend (a) with pre-wet flow rate of $700 \mathrm{ml} / \mathrm{min}$ and without the high spray bar of DI water and (b) pre-wet flow rate of $200 \mathrm{ml} / \mathrm{min}$ and high spray bar of DI water (Reproduced from Ref. [43], with permission from Elsevier).

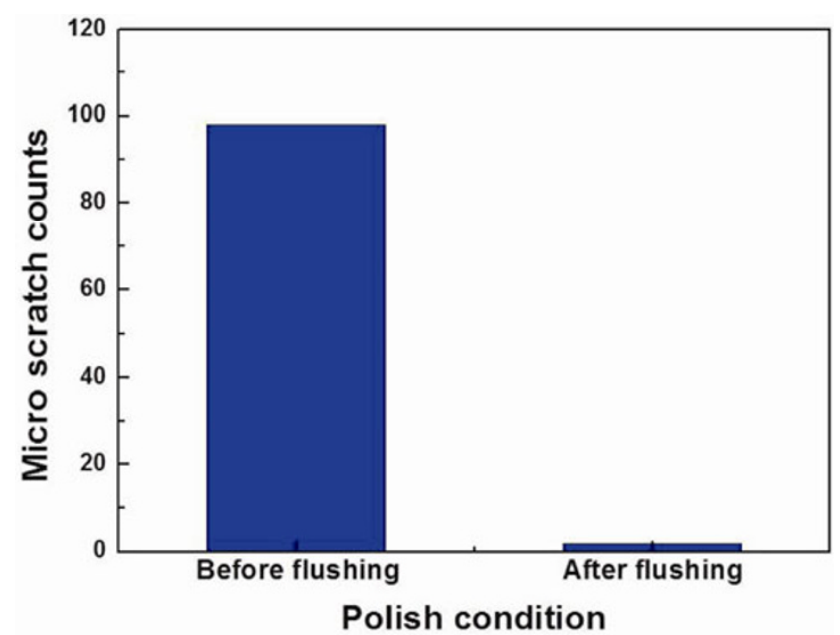

Fig. 10 Effect of flushing slurry line [44].

analysis method to quantify the large particle concentration (LPC). Also, the correlation between LPC in fumed silica slurries and scratch formation during
CMP were established. Figure 11 shows the correlation, which is linear when considering values of LPC over $0.469 \mu \mathrm{m}$. Also, an example of LPC levels of filtered slurries (A, C, D, E, F, and G) with scratch count results is shown in Fig. 12.

Several researchers used modified abrasive particles to reduce the surface defects such as scratches [48-52]. Generally, a mixed abrasive slurry and various dispersants were used for the development of fine slurries $[49,50]$. Coutinho et al. [48] synthesized composite particles containing ceria nanoparticles dispersed within cross-linked, polymeric microspheres formed by copolymerization of $N$-isopropylacrylamide (NIPAM) with 3-(trimethoxysilyl)propyl methacrylate (MPS), which can used as novel abrasive particles for CMP. As a result, surfaces polished using composite particles showed lower topographical variations and surface roughness than surfaces polished using ceria 


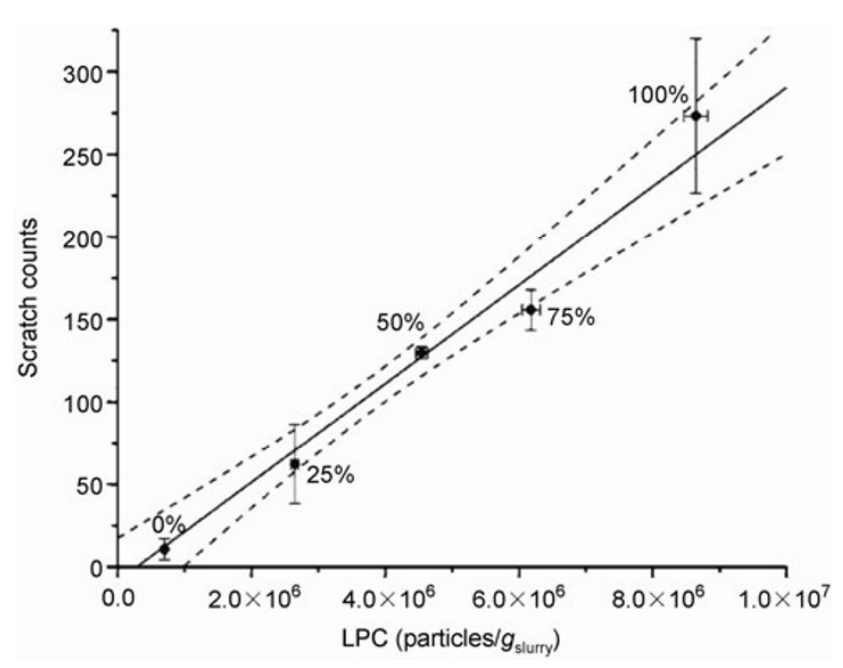

Fig. 11 Correlation between scratch counts and LPC determined for particles with diameter $\geqslant 0.469 \mu \mathrm{m}$ (Reprinted with permission from Ref. [47]. Copyright 2006, The Electrochemical Society).

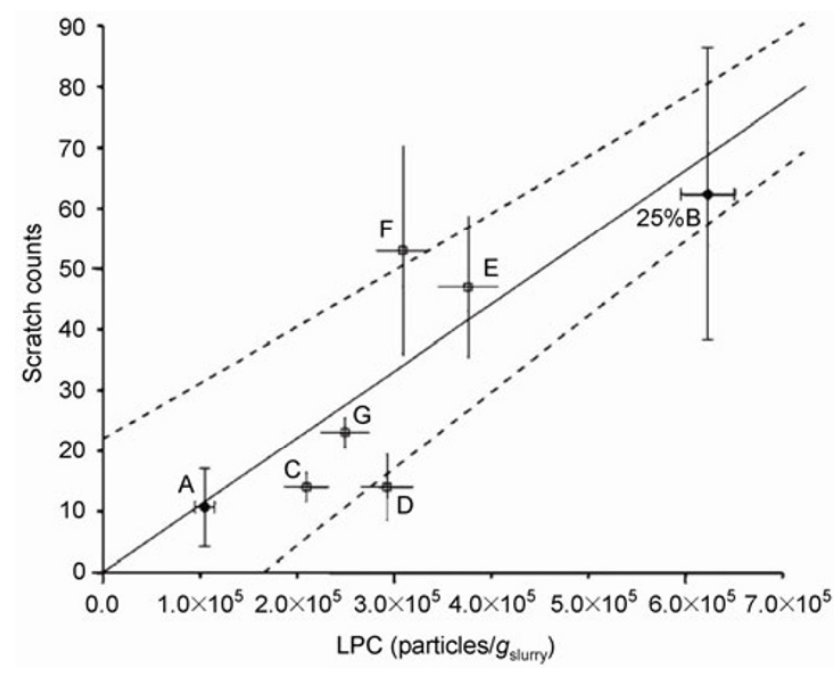

Fig. 12 Expansion of the low scratch count region of the correlation between scratch counts and LPC determined for particles with diameter $\geqslant 0.68 \mu \mathrm{m}$ (Reprinted with permission from Ref. [47]. Copyright 2006, The Electrochemical Society).

nanoparticles (Fig. 13). Also, optical microscopy images of post-CMP oxide surfaces are shown in Fig. 14. Commercial ceria particles resulted in severe scratches on the oxide surface when compared to the composite ceria particles.

Furthermore, some researchers have proposed surface modified abrasive particles for CMP slurry formulations [51-54]. Lei and Zhang [51] used alumina/silica core-shell abrasive particles to get a uniform surface with fewer scratches. Alumina particles

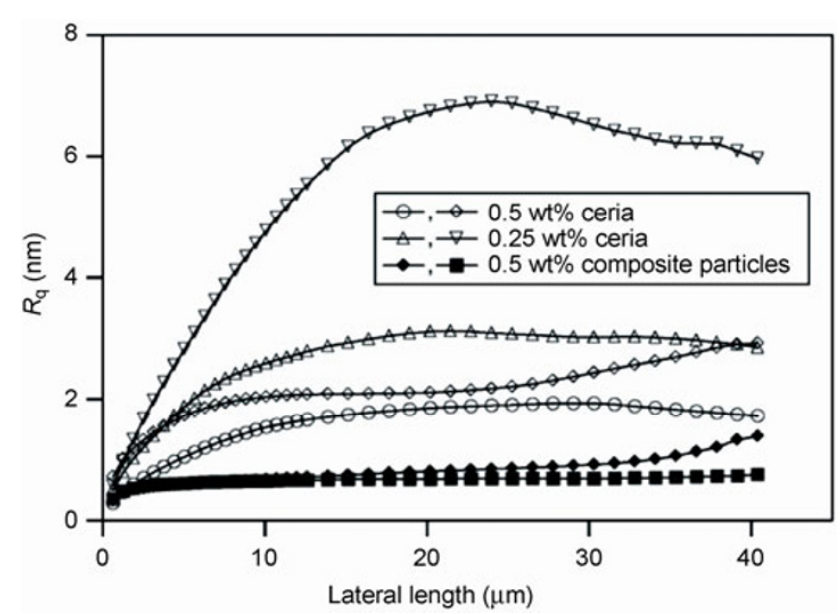

Fig. 13 Surface roughness of the polished wafer (Reproduced from Ref. [48], with permission from Elsevier).

with a higher hardness generated more and deeper scratches. The $\alpha$-alumina/silica core-shell particles were prepared by mixing $0.2 \mathrm{~mol} / \mathrm{L} \mathrm{Na}_{2} \mathrm{SiO}_{3}$ and $1 \mathrm{wt} \%$ $\mathrm{H}_{2} \mathrm{SO}_{4}$ solutions with an $\alpha$-alumina dispersion and simultaneously stirring at the reaction temperature. The $\mathrm{pH}$ of the mixture was maintained between 9 and 10. Synthesized alumina/silica core-shell abrasives were characterized using Fourier transform infrared (FTIR) spectrocopy, X-ray photoelectron spectroscopy (XPS), secondary ion mass spectroscopy (SIMS), and a zeta potential analyzer. Figure 15 shows the SEM image of alumina particles before and after coating. When a composite abrasive-based slurry was used for the polishing, surface roughness was significantly decreased; the optical microscope images of disk substrate are shown in Fig. 16.

On the other hand, novel polymer-core silica-shell composites were proposed by Armini et al. [52, 53]. Polymethyl methacrylate (PMMA)-based terpolymer particles (diameter $350 \mathrm{~nm}$ ) were coated with colloidal silica particles. The coating was performed either by creating chemical bonds using a silane coupling agent (composite $\mathrm{A}$ ) or by adjusting the $\mathrm{pH}$ to form electrostatic attractive interactions between the core and the shell (composite B). They focused on tuning the mechanical properties of the polymer core by varying its synthesis parameters. The major advantage of the silica coating is that it can be easily modified in terms of its surface chemistry and morphology. Also, composite particles are aimed at improving the CMP 


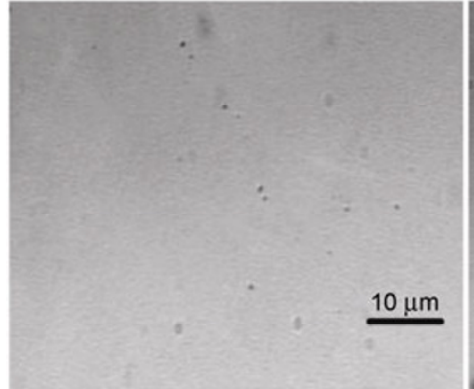

(a)

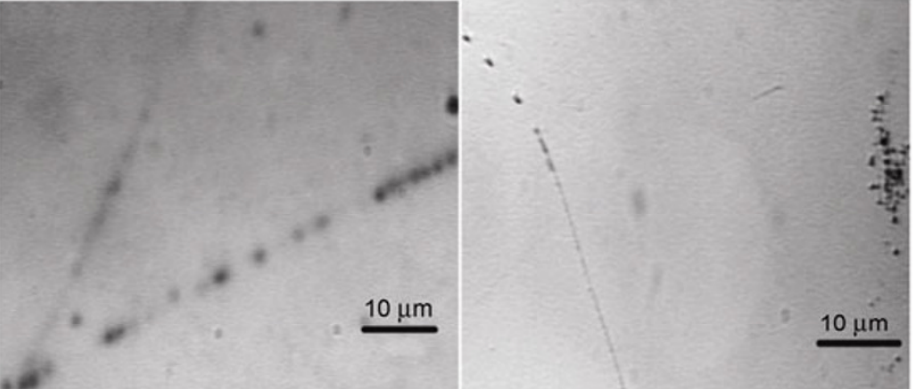

(b) (c)

Fig. 14 Optical microscopy images of silicon dioxide films polished with slurry containing (a) $0.5 \mathrm{wt} \%$ composite particles, (b) $0.5 \mathrm{wt} \%$ $\mathrm{CeO}_{2}$ nanoparticles, and (c) $0.25 \mathrm{wt} \% \mathrm{CeO}_{2}$ nanoparticles (Reproduced from Ref. [48], with permission from Elsevier).

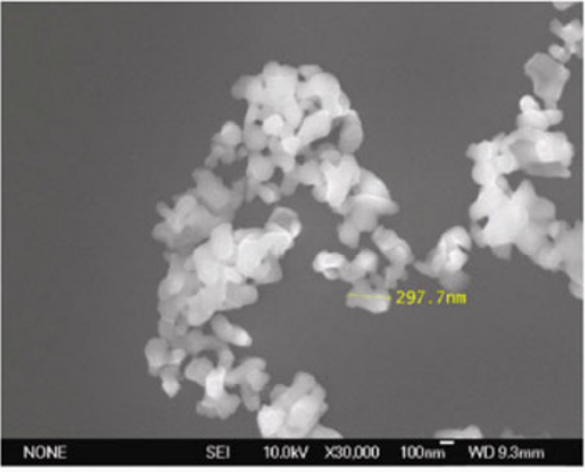

(a)

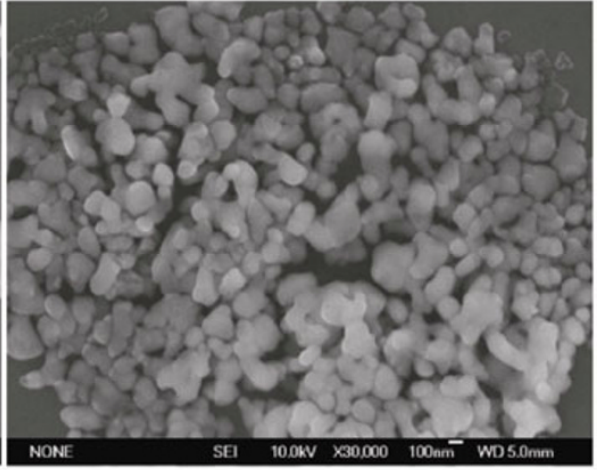

(b)

Fig. 15 SEM image of alumina particles (a) before and (b) after coating (Reproduced from Ref. [51], with permission from Elsevier).

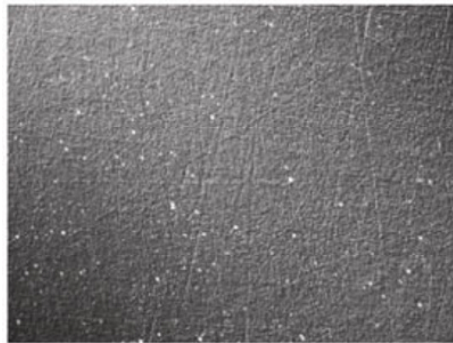

(a)

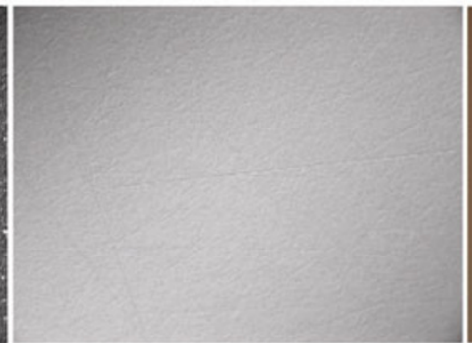

(b)

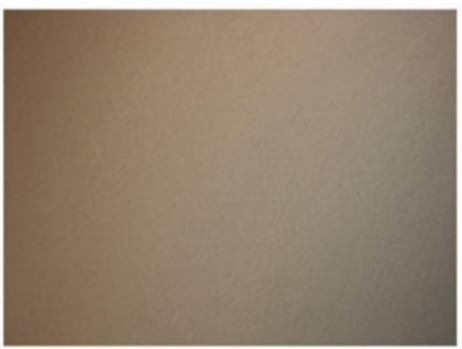

(c)

Fig. 16 Optical microscope images of disk substrates polished in slurries containing different abrasives (a) before polishing (200×), (b) polished using pure alumina slurry $(200 \times)$ and (c) polished using composite abrasive (with 10 wt\% coating) slurry (200×) (Reproduced from Ref. [51], with permission from Elsevier).

process of soft materials due to the cushion-like effect arising from the elastic properties of the core, which allow the composites to easily adapt to the pad asperities (Fig. 17).

Oxide removal rate and scratch generation were evaluated using four types of abrasive particles (30 and $90 \mathrm{~nm}$ colloidal silica particles, $350 \mathrm{~nm}$ polymer particles, composite A and B). Figure 18 shows the oxide thickness loss after 1 min of CMP using different abrasive particles. For the silica abrasive, thickness loss decreased with increasing particle size. In the case of two composite particles, total defect counts were different. Composite B particles are spherical in shape and are more similar to the colloidal silica particle. Also, the larger size of colloidal silica shows a higher number of defects level than the smaller size of 


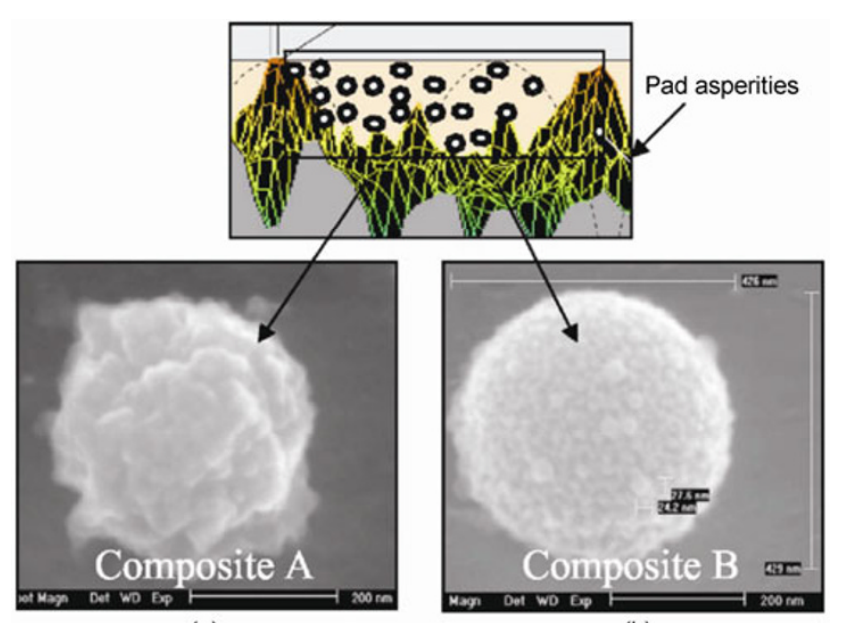

(a)

(b)

Fig. 17 Schematic diagram depicting $\mu$-scale phenomena occurring during CMP. SEM images of (a) composite A and (b) composite $B$ abrasives (Reprinted with permission from Ref. [52]. Copyright 2007, The Electrochemical Society).

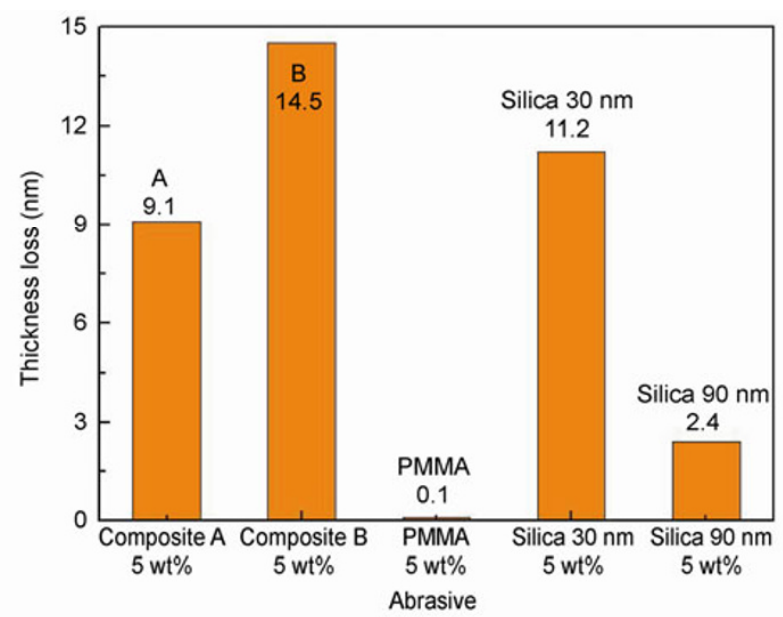

(a)

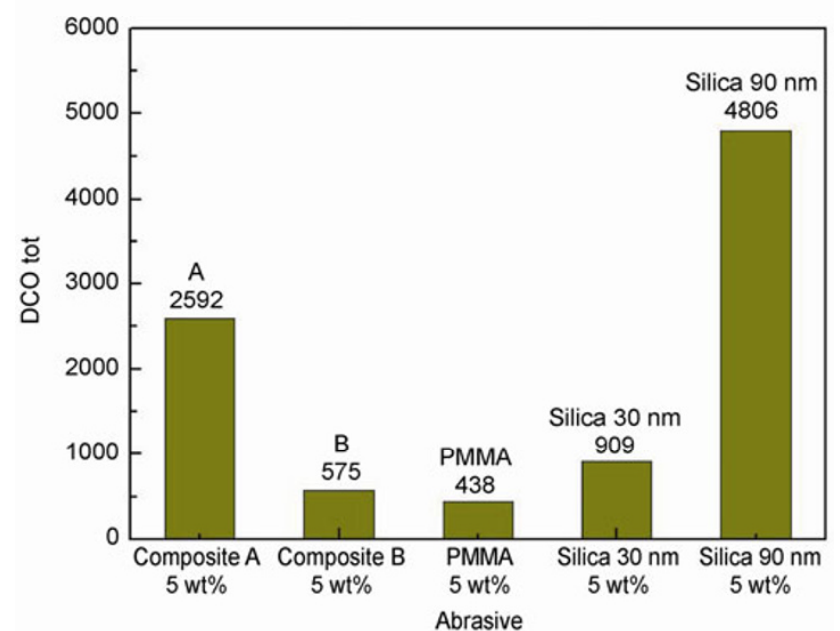

(b)

Fig. 18 (a) Thickness loss vs. abrasive type and (b) total defect count vs. abrasive type after oxide CMP at pH 10 [52]. colloidal silica. The interaction force and composite particle morphology were also described in other works $[53,54]$. Based on the average pull-off force vs. $\mathrm{pH}$ plot, qualitative agreement between the measured adhesion forces and the material removal rate was reached [53]. Furthermore, the depth of the scratch increased with increasing abrasive size of fumed silica abrasive. Overall, fewer and shallower scratches were detected for composite B particle with a colloidal silica shell compared with only colloidal silica due to the effect of the elasticity of the polymer core [54].

As mentioned earlier, slurry is one of the major consumables for the CMP process. Slurry consists of fine abrasives which act as a source for scratch generation. A typical CMP slurry consists of abrasives, additives, and a $\mathrm{pH}$ buffing agent. The slurry distribution system consists of a slurry tank, distribution pumps, a pressure gauge, a flow meter, and a pressurized air supply outlet/inlet [55]. A schematic representation of the slurry distribution system is shown in Fig. 19. Stability of the slurry is critical in the CMP process. During pumping and mixing of the slurry, particles tend to agglomerate due to the $\mathrm{pH}$ shock, the dilution effect or the temperature change. $\mathrm{pH}$ shock may be due to the dilution effect or mixing effect caused by the additives (as in the case of a two component slurry) [56]. Stress-induced particle agglomeration has already been extensively studied $[55,57,58]$.

Stress-induced particle agglomeration can be explained by the Smoluchowski theory based model,

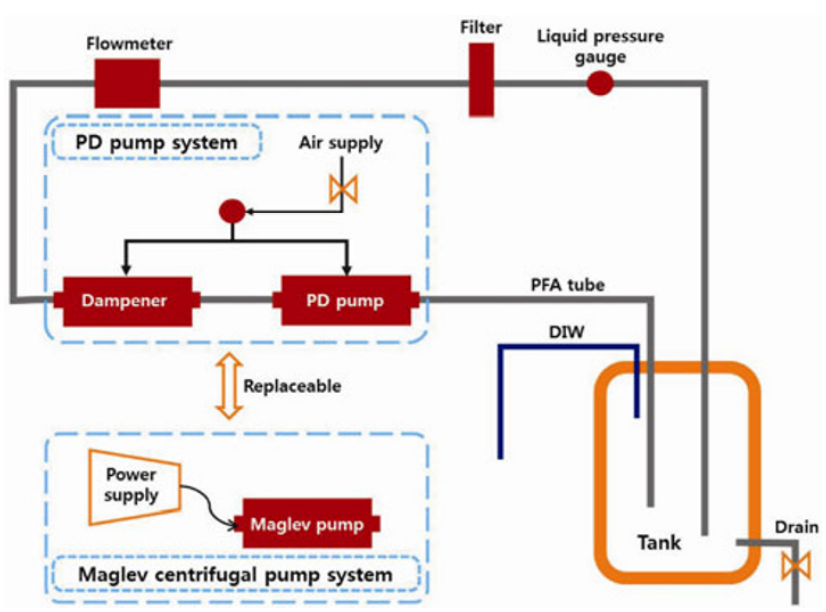

Fig. 19 Schematic illustration of the slurry distribution system [55]. 
which considered the shear flow and the electrostatic interaction between particles. It was assumed that particle collisions were binary and proportional to the particle concentration. Chang et al. [55] simulated the aggregation rate of $k$-fold aggregates, $\mathrm{d} N_{k} / \mathrm{d} t$, which is given by the time evolution of the cluster size aggregates, $i$ and $j$-fold.

$$
\begin{gathered}
\frac{\mathrm{d} N_{k}}{\mathrm{~d} t}=\frac{1}{2} \sum_{i+j=k}^{l=k-1}\left(k_{i j} / W_{i j}\right) N_{i} N_{j}-N_{k} \sum_{k=1}^{\infty}\left(k_{k i} / W_{k i}\right) N_{i} \\
k_{i j}=\frac{4}{3} G\left(a_{i}+a_{j}\right)
\end{gathered}
$$

where the aggregation constant, $k_{i j}$, is a function of the shear rate $(G)$ and particle size $(a)$. The stability ratio $(W)$ is the ratio of the rapid aggregation rate without electrostatic interaction to the slow aggregation rate in the presence of electrostatic interactions between particles. According to this model, the shear flow causes particles to approach each other during slurry delivery. When van der Waals forces are greater than the repulsive inter-particle force, particle agglomeration occurs. The degree of particle agglomeration is influenced by the slurry properties (e.g., interparticle forces), external shear stress (i.e., type of pump), and the number of turnovers of the slurry. They found that a magnetically levitated centrifugal pump resulted in lower stress effects on particle agglomeration and did not increase the concentration of oversized particles, as shown in Fig. 20 [55]. Also, the defectivity was evaluated using the low- $k$ dielectric CMP. Optical microscopy images of the low- $k$ dielectric film are shown in Fig. 21.

\subsection{Pad surface properties and pad debris}

CMP is a complex interaction process between the wafer surface and the consumables. The CMP polishing pad is an important consumable among all other consumables, and has a dominating effect on the material removal rate [59]. The structure and material properties determine the material removal rate and planarization ability $[1,60]$. Usually, the polishing

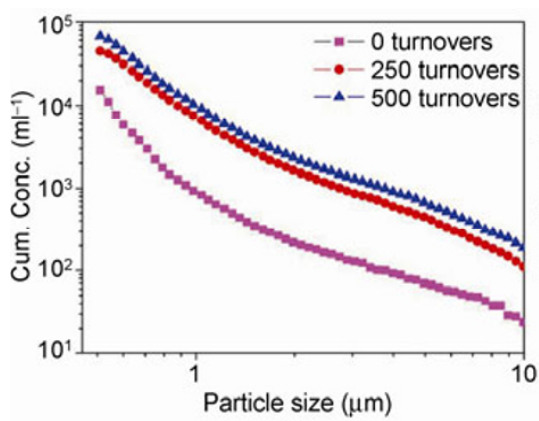

(a)

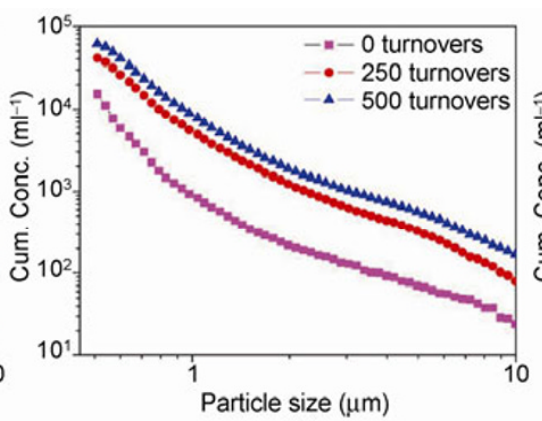

(b)

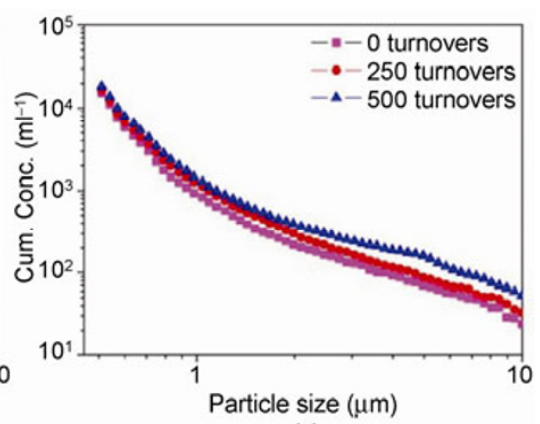

(c)

Fig. 20 Cumulative concentration vs. particle size at 0, 250, and 500 turnovers for (a) bellows, (b) diaphragm, and (c) magnetically levitated centrifugal pump system (Reprinted with permission from Ref. [55]. Copyright 2009, The Electrochemical Society).

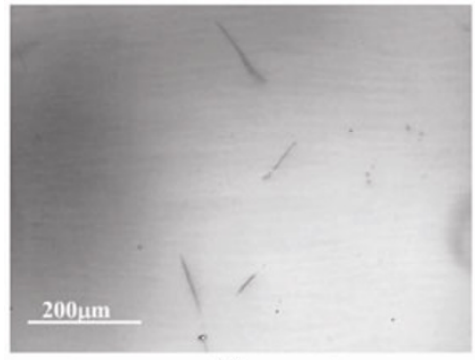

(a)

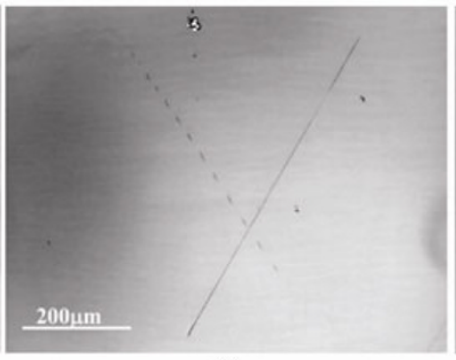

(b)

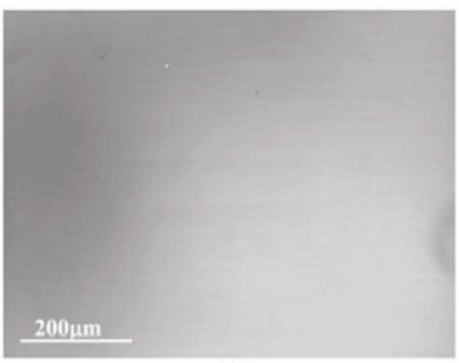

(c)

Fig. 21 Optical microscopy images of BD1 wafers polished by circulated slurries using (a) bellows, (b) diaphragm and (c) magnetically levitated centrifugal pump system (Reprinted with permission from Ref. [55]. Copyright 2009, The Electrochemical Society). 
pad contains both pores and grooves, which help for better planarization $[61,62]$. The pores of a pad act as a lake, store the slurry particles, and enhance the contact time between slurry particles and the wafer. Grooves provide a channel for efficient and uniform slurry distribution across the pad surface to the wafer surface. These parameters determine the slurry transportation and contact area at the pad/wafer interface $[1,5,7,59,62]$. Choi et al. [62] studied the synergistic role of pores and grooves of a pad in forming the scratches (especially chatter mark scratches) using three types of pads. Pad with only pores, only grooves, and both pores and grooves were investigated to understand its effect on scratch formation. Figure 22 shows the SEM images of scratch shapes formed on the STI patterned wafers polished using three types of pads. Different types of pads generated different types of scratches. Pad-3 (containing both pores and grooves) generated short chatter mark-shaped scratches compared with the other types of pads.

Figure 23 shows the effect of pad type on scratch ratio (percentage of scratches/defective die, i.e., the number of scratches formed on 100 defective dies) and removal rate during the STI CMP process. Scratch formation was found to be higher in the contact regime and lower in the lubricating regime. The contact regime exists when the pad contains only grooves [63], and the lubricating regime exists when the pad contains pores [64]. Optimum conditions were obtained in the presence of a lubricating regime with fewer scratch sources present on the pad [62]. Also, the presence of grooves helps to discharge most of the scratch sources generated during the process away from the waferpad contact [65].

Both the structure of polishing pads, such as pores and grooves, and the hardness of the pad affect the MRR and generate the scratches. Hsien et al. [66] reported scratch generation by comparing the hard and soft pads. It was reported that the soft pad with lower pressure generated fewer scratches [66, 67]. Furthermore, Eusner et al. [68] quantitatively analyzed the topography and material properties of fresh and

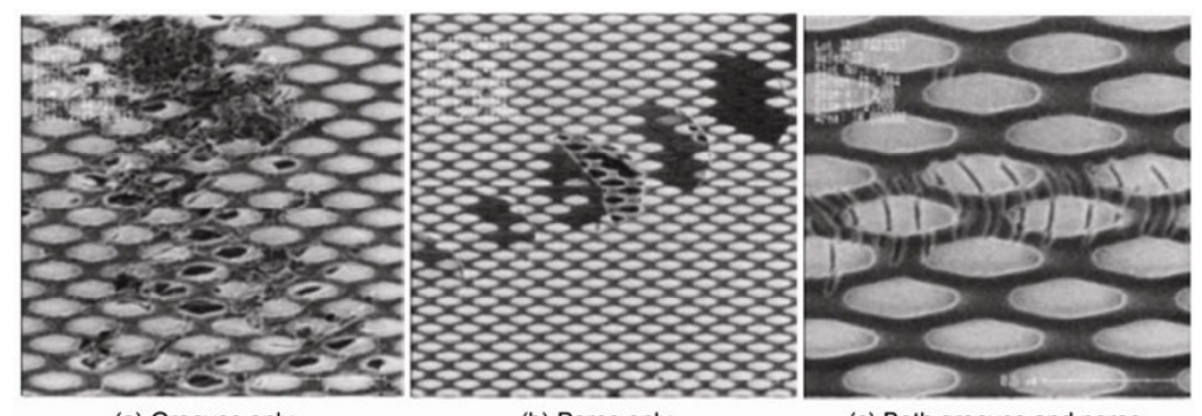

(a) Grooves only

(b) Pores only

(c) Both grooves and pores

Fig. 22 SEM images of scratches formed on STI-patterned wafers after CMP using pads with (a) only grooves (pad-1), (b) only pores (pad-2), and (c) pores and grooves (pad-3) [62].

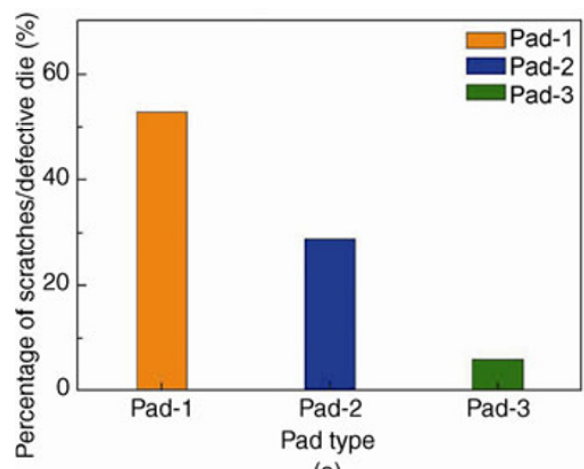

(a)

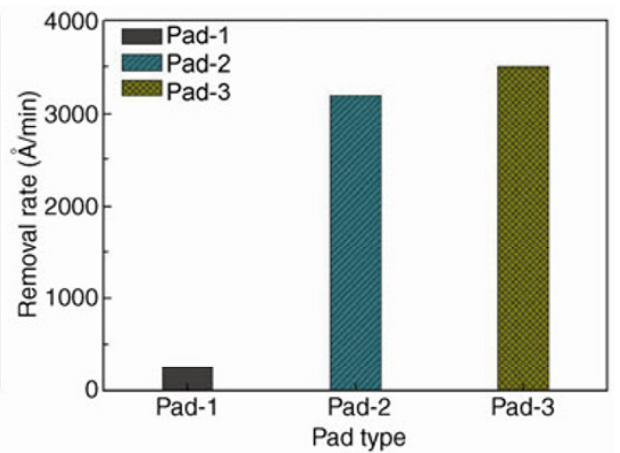

(b)

Fig. 23 (a) Scratch ratio on the STI-patterned wafer, and (b) MRR of blanket oxide wafer with ceria slurry as a function of pad type [63]. 
broken-in pads to correlate with scratch generation on $\mathrm{Cu} \mathrm{CMP}$. The hardness and modulus of the pad were measured, and the change in pad asperity radius of curvature was measured during pad break-in with a blanket $\mathrm{Cu}$ wafer in the slurry. It was found that the average pad modulus decreased from 0.66 to $0.34 \mathrm{GPa}$ and the average pad hardness decreased from 0.05 to $0.03 \mathrm{GPa}$ through pad break-in. In contrast, the average pad asperity radius of curvature increased from 16 to $93 \mu \mathrm{m}$ as a result of pad break-in, which induced a reduction in severe scratch formation. Scratches were detected using an optical scanning method after polishing using the fresh and broken-in pad with only water. The reason for using water was to isolate the scratches generated by the pad from the slurry particles. Also, the critical pad asperity radius of curvature was based on asperity deformation (i.e., elastic or plastic).

During the CMP process, the pad surface can undergo plastic deformation and the surface becomes smoother as the pores are filled with the pad materials [15]. Using a glazed pad causes the removal rate to drop significantly [69]. Polishing pads were conditioned with a diamond conditioner to provide consistent performance and to prevent the glazing effect. Usually, diamond grits used for pad conditioning are attached to an alloy substrate using electrochemical deposition methods [8]. Yang et al. [70, 71] investigated the CMP process based on material removal rate and scratch defects by studying the pad interaction and conditioner effect using two types of polishing pads: a porous pad and a solid pad with micro holes (Fig. 24). When a solid pad with micro holes was used with a fumed silica slurry and a $180 \mu \mathrm{m}$ diamond grit conditioner, the material removal rate decreased by approximately $10 \%$ compared with the porous pad. However, the scratch defects were reduced when compared with the porous pad which is shown in Fig. 25. In order to increase the removal rate obtained using a solid pad with micro holes to a level comparable to a regular porous pad, various diamond conditioners with diamond size ranging from 70 to $130 \mu \mathrm{m}$ were adopted. Also, pad surface roughness and contact area were analyzed to understand the removal rate and the scratch generation. Figure 26 shows the effect of

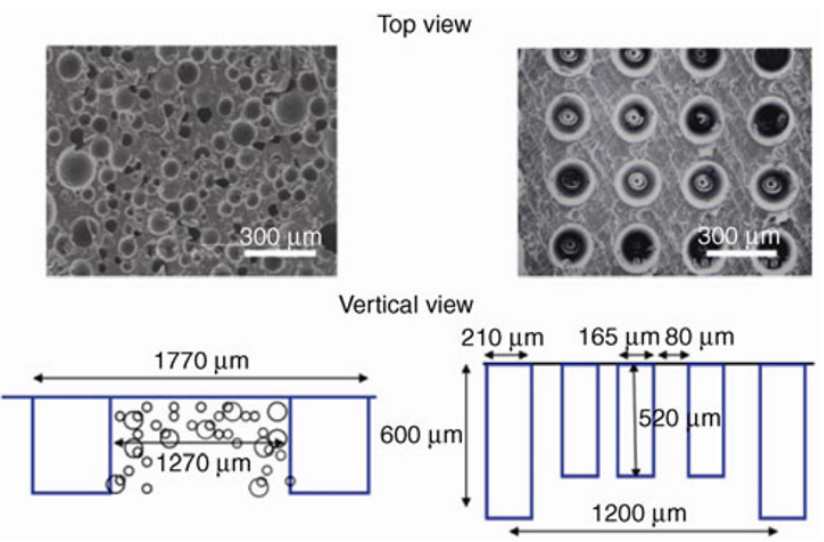

Fig. 24 SEM micrographs (top) and schematics (bottom) of (a) porous pads and (b) solid pads (Reproduced from Ref. [70], with permission from Elsevier).

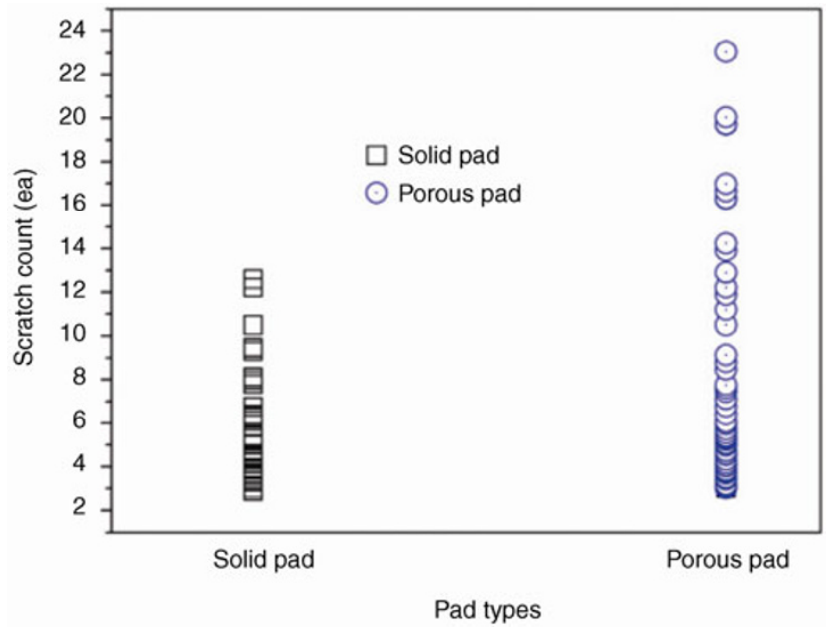

Fig. 25 Scratch level on STI patterned wafers generated by porous and solid pads with $180 \mu \mathrm{m}$ diamond conditioner (Reproduced from Ref. [70], with permission from Elsevier).

diamond size of conditioner on the removal rate and scratch generation. It was found that the micro holes in the pad acted as a defect source or coarse particle reservoir to prevent micro scratching during the process [71]. They reported optimized results of solid pads with micro holes using the hole depth control procedure to reduce the defects.

As mentioned earlier, pad debris can be generated due to tearing of the pad by the conditioner. Prasad et al. [72] studied the generation of pad debris and its characterization. They reported that pad debris could act as a main scratch source, resulting in scratches with several size ranges with irregular shapes, mostly in agglomerated form. It was also proposed that the surface properties were changed by their adsorption 


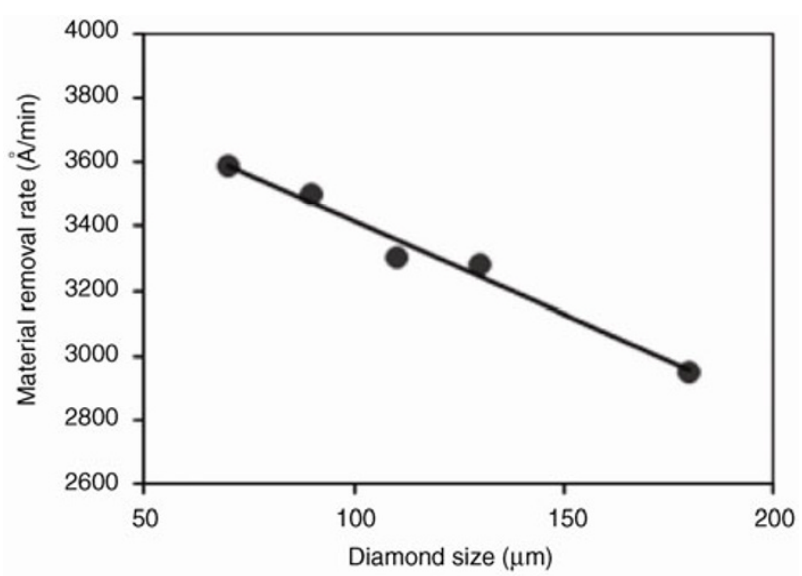

(a)

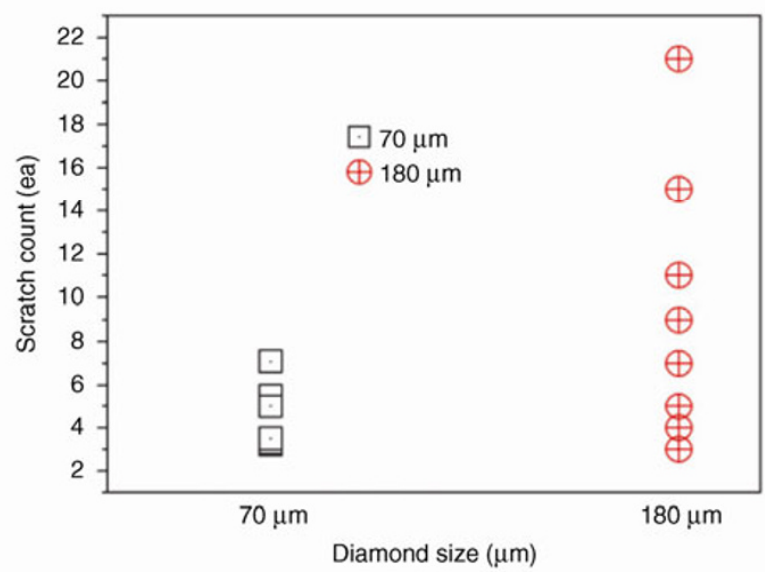

(b)

Fig. 26 The effect of diamond size on (a) removal rate and (b) scratch generation (Reproduced from Ref. [70], with permission from Elsevier).

with abrasive particles. Figure 27 shows FESEM images of fresh pad particles and pad debris generated using DI water and silica abrasive particles. Park's group [73] also investigated the scratch number using the three different scratch source (vis., pad debris, dried particles, and diamond particles) on scratch formation comprehensively with their classification. Figure 28 shows the material removal rate and generated scratch number as a function of scratch source. A small amount of impurity in slurry did not affect the MRR. However, scratch number was affected by the kind of scratch sources. Figure 29 shows the distribution of scratchess formed by adding different scratch sources during polishing. Borken chatter type of scratches was easily formed when dry slurry paritcles were added but group chatter when pad debris were added. Yang et al. [74] measured the pad surface hardening

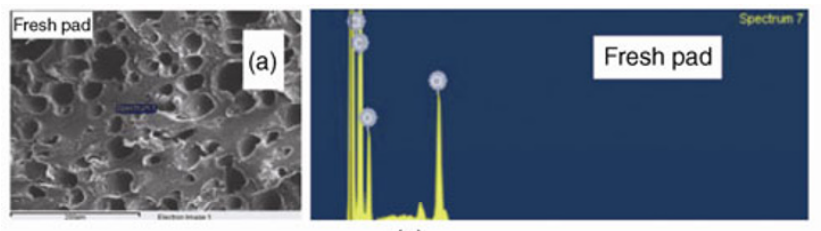

(a)

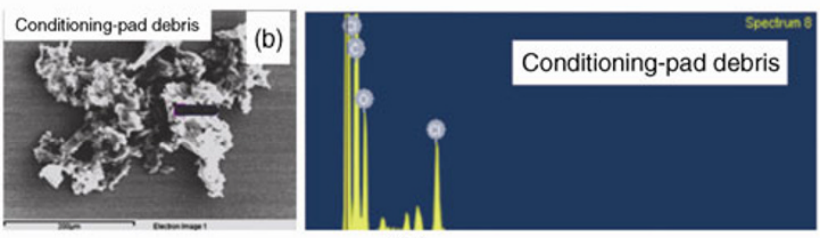

(b)

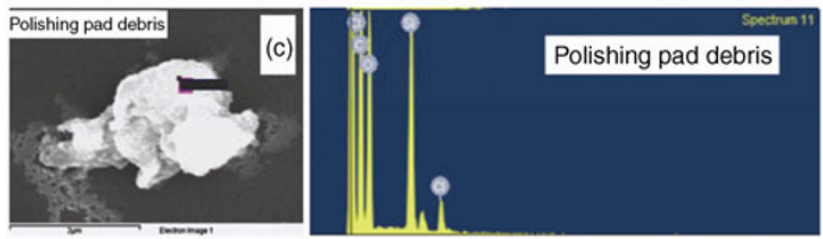

(c)

Fig. 27 SEM image and EDX analysis of (a) fresh pad, (b) pad debris with only DI water, and (c) pad debris with silica slurry [72].

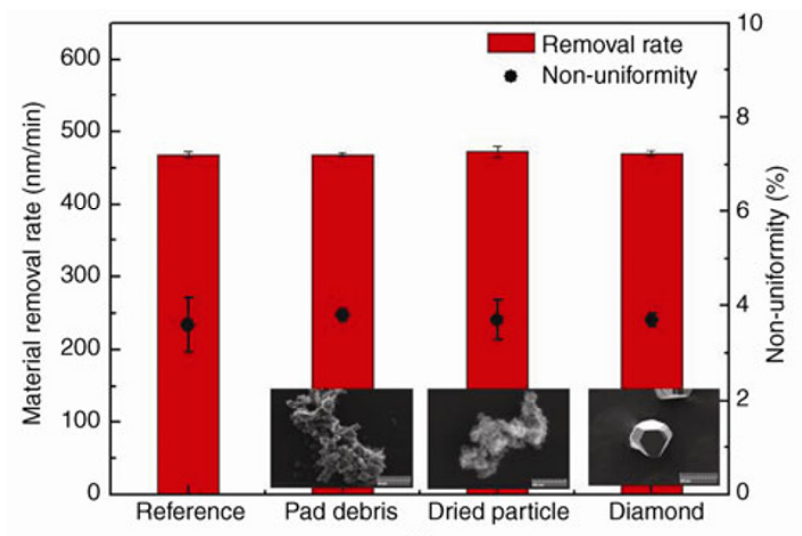

(a)

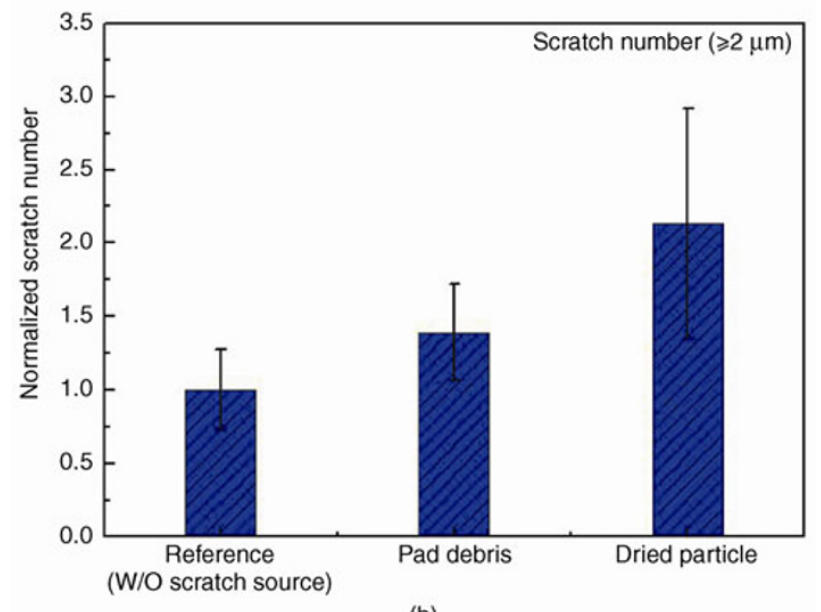

(b)

Fig. 28 (a) Material removal rate, non-uniformity and (b) the variation of number of scratches formed with addition of different scratch sources [73]. 


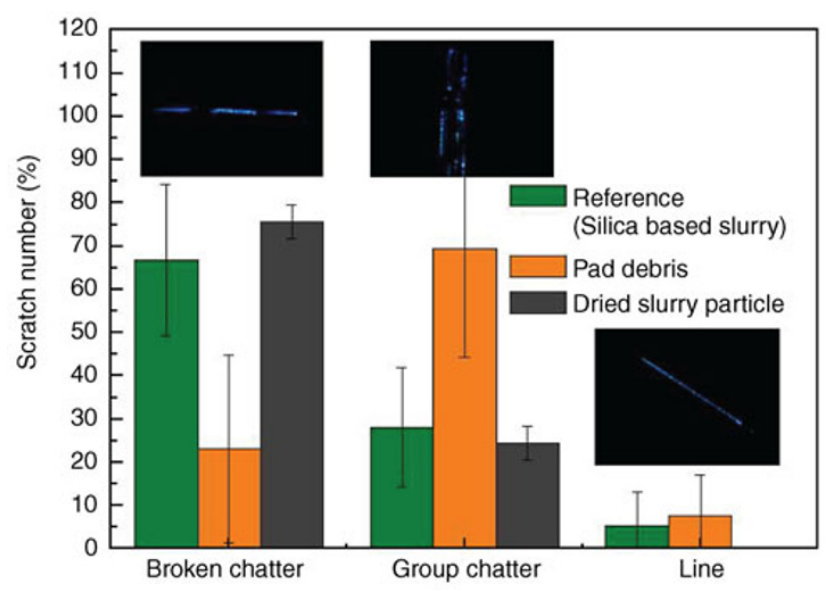

(a)

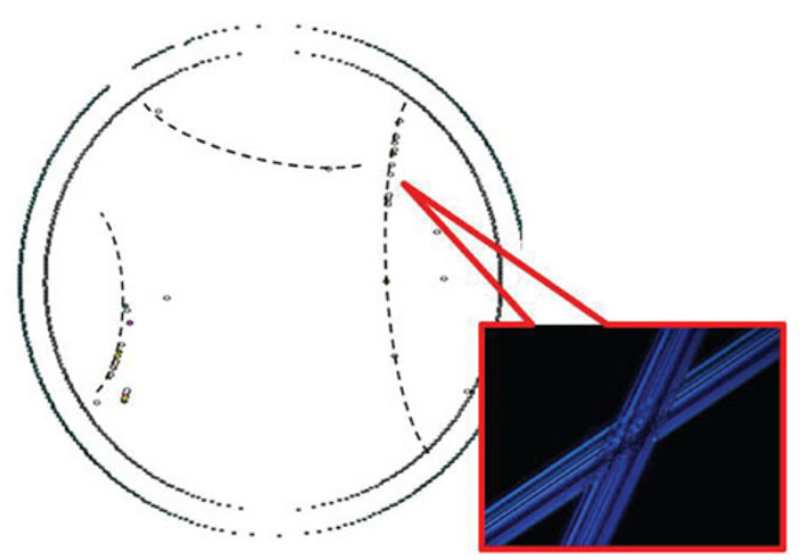

(b)

Fig. 29 (a) Effect of addition of pad debris, dried slurry particle and (b) diamond particles on distribution of scratch shapes formed on oxide surface after CMP process with silica slurry [73].

phenomenon based on force-distance (F-D) curves. It was found that the interaction between abrasive particle and polyurethane pad under tribo-mechanical action could change the pad surface hardness. Benner et al. [77] used a vacuum cleaner to remove the pad debris and agglomerated large particles from the pad; they dubbed this process the pad surface manager (PSM). Figure 30 contains a plot of light-point defects measured using a Tencor 6220 on polished oxide wafers using different levels of PSM vacuum. The data were normalized to that observed without vacuum. As the PSM vacuum level was increased, CMP induced wafer defects decreased. Approximately a $50 \%$ reduction in light-point defects was observed using the PSM technique.

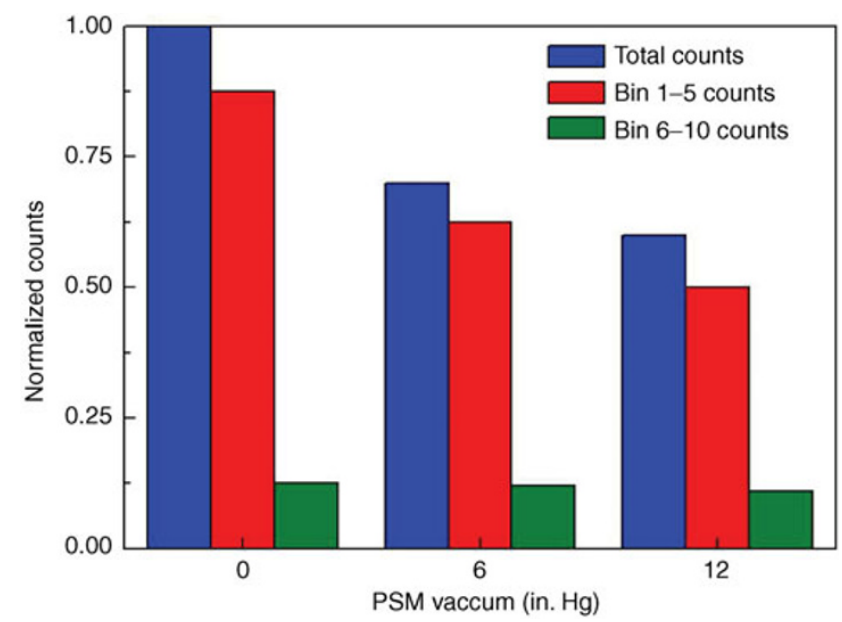

Fig. 30 A plot of the dependence of light-point defect counts, measured with a Tencor 6220 on oxide wafers, as a function of PSM vacuum level. A reduction of nearly $50 \%$ was observed as a PSM vacuum [77].

\section{Scratch formation mechanism}

Brittle fracture can occur by three basic types of static indentations: Hertzian cracks, radial cracks, and lateral cracks (Fig. 31) [78-80]. Hertzian cracks are cone cracks that are created from a spherical indenter. Radial cracks are semi-circular cracks perpendicular to the glass surface from a sharp indenter, and lateral cracks are cracks that run generally parallel to the glass surface, which are also typically created by a sharp indenter. Suratwala et al. [78, 79] measured the distribution and characteristics of surface crack (subsurface damage) formation during grinding on fused silica glass using a surface taper polishing technique. The observed surface cracks were characterized as near-surface lateral- and deeper trailing indent-type fractures. They showed that only a small fraction of the abrasive particles are being mechanically loaded and causing fracture, and most likely it is the larger particles in the abrasive particle size distribution that bear the higher loads. Surface damage depth increased with load and with a small amount of larger contaminant particles, which is based on the brittle facture models (Fig. 32) [78]. Also, the surface damage depth distribution has been related to the length distribution to gain insight in effective size distribution of particles participating in the fracture. Figure 33 shows the various types of scratches that were observed as a result 


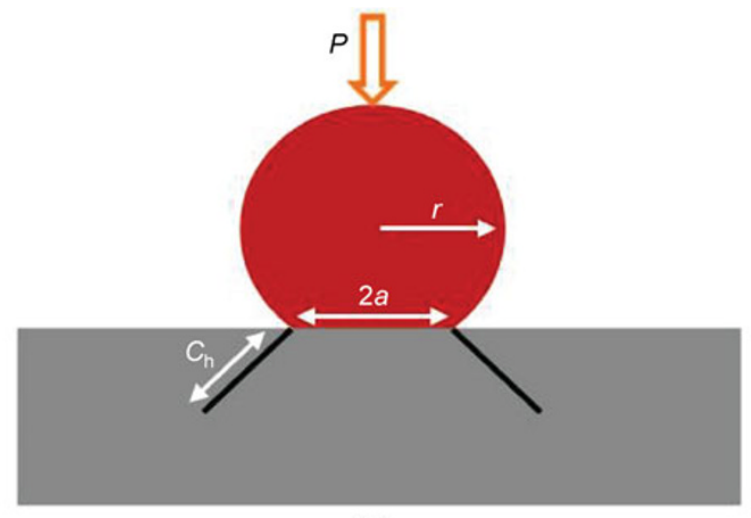

(a)

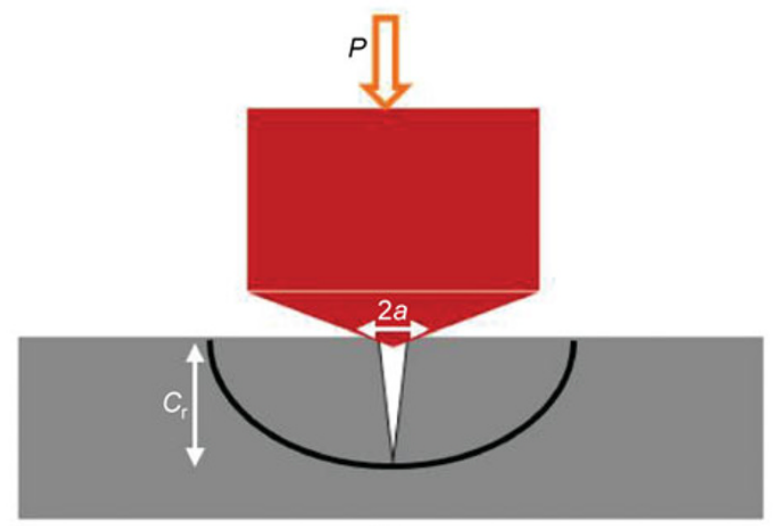

(b)

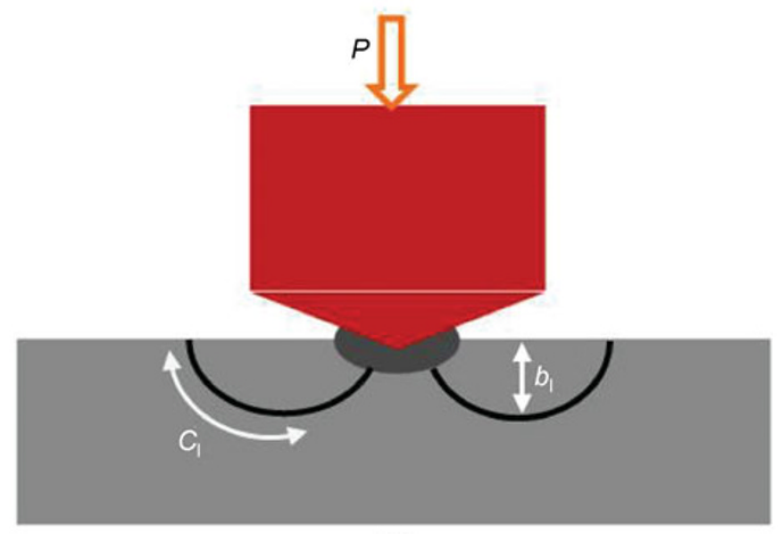

(c)

Fig. 31 Schematic illustrations of the fracture geometry of the idealized fractures created by static indentation: (a) Hertzian cone crack from a blunt indenter, (b) radial or median cracks from a sharp indenter, and (c) lateral crack from a sharp indenter [78].

of addition of rogue particles [81]. These scratches were classified into three basic categories: (1) plastic scratches that show no brittle fracture, (2) brittle scratches, which only have cracks (trailing indent or lateral) and (3) mixed scratches that contain both plastic modification and cracks.

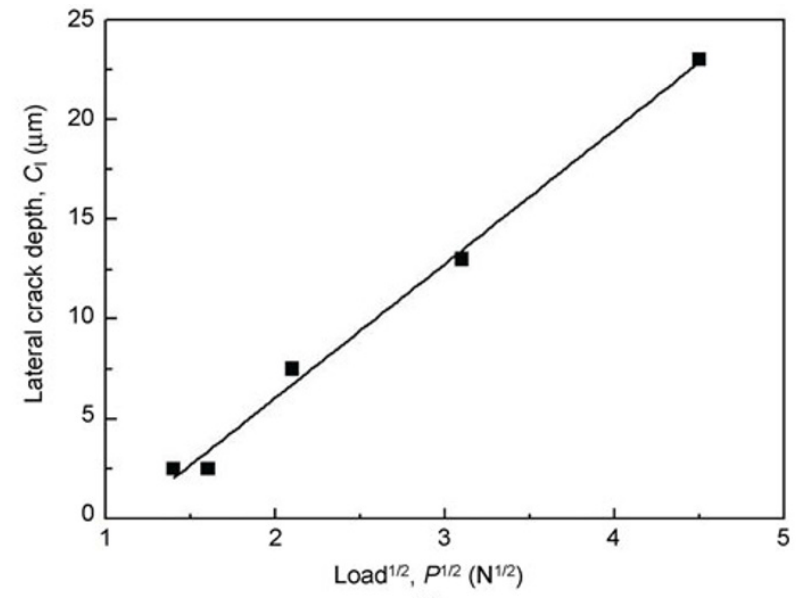

(a)

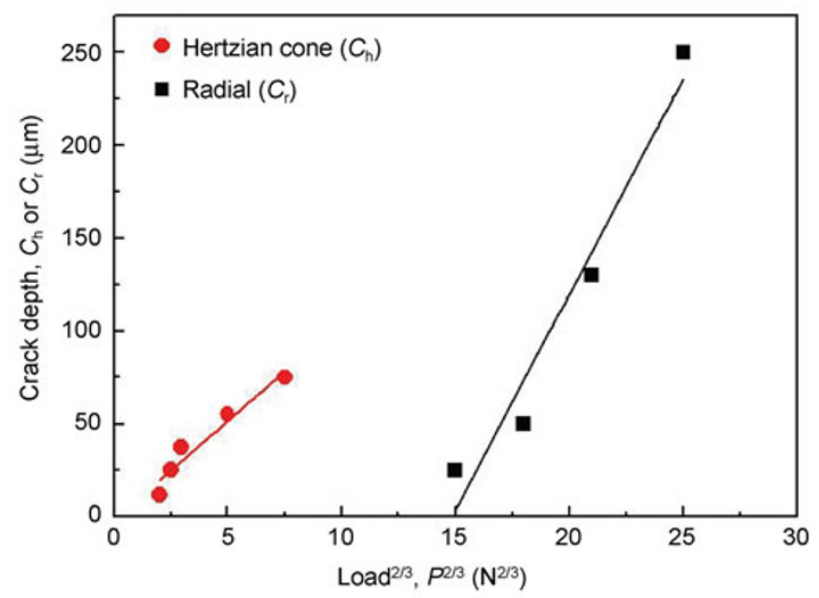

(b)

Fig. 32 (a) Lateral crack depth as a function of $\operatorname{load}^{1 / 2}$ and (b) Hertzian cone depth and radial crack depth as a function of $\operatorname{load}^{2 / 3}[78]$.
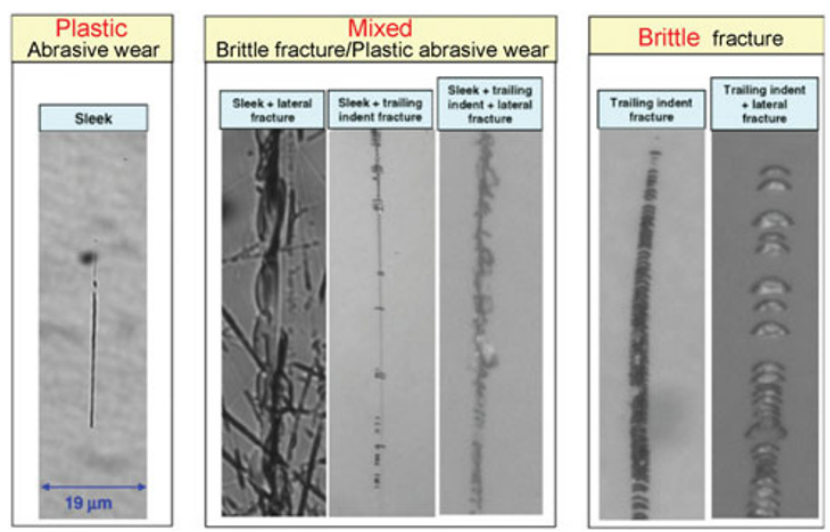

Fig. 33 Categories of different types of scratches observed in fused silica sample (Reproduced from Ref. [29], with permission from Elsevier).

Furthermore, Ring et al. [29] reviewed the mechanical properties and fracture mechanics of materials in order 
to understand the surface damage caused during CMP. The resulting failure was predicted by various mechanical wear (or scratching) equations depending upon the assumption of plastic deformation or brittle fracture (Fig. 34). The wear rate goes from reasonably low rates for plastic wear to rates with higher orders of magnitude for brittle fracture. The wear rate transition occurs at a threshold normal load, i.e.,

$$
L_{\mathrm{Nc}} \sim 2 \times 10^{5} K_{\mathrm{Ic}}^{4} / H^{3}
$$

where $H$ is the hardness of the surface being damaged and $K_{\mathrm{Ic}}$ is its fracture toughness. In the case of plastic deformation, the differential volume, $\mathrm{d} V$, of material removed per unit length, $\mathrm{d} x$, of the scratch depends upon the load of the abrasive point normal to the surface, $L_{\mathrm{N}}$, and the mechanical properties of the materials comprising the surface as follows:

$$
\mathrm{d} V / \mathrm{d} x \sim\left(L_{\mathrm{N}} / H\right)
$$

This equation assumes that the abrasive point is harder than the material comprising the surface. In the case of brittle fracture, the fracture wear rate could be represented as follows:

$$
\mathrm{d} V / \mathrm{d} x \sim(E / H)^{4 / 5} K_{\mathrm{Ic}}^{-1 / 2} H^{-5 / 8} L_{\mathrm{N}}^{9 / 8}
$$

where $E$ is Young's modulus. Ring et al. considered each of these scratching particles to be attached to the tip of an asperity or, if larger than an asperity, to be pressed into the pad to determine the depth distribution of the scratches due to both abrasive particles

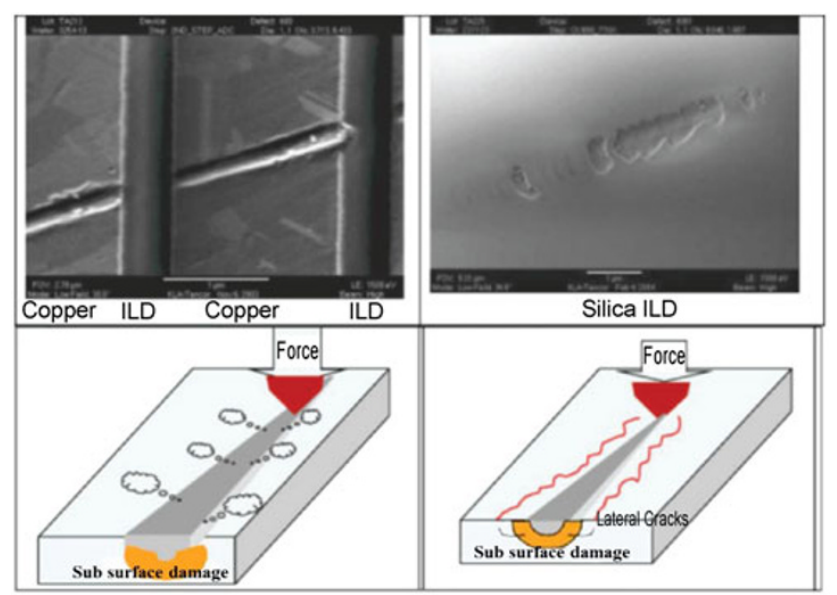

Fig. 34 Schematic of (a) plastic deformation and (b) brittle fracture (Reprinted with permission from Ref. [29]. Copyright 2007, The Electrochemical Society). and particles impurities, which were not spherical but angular in shape. Also, the distribution of radii of curvature for the point of the impurity particle in contact with the wafer surface was considered. Hence, the plastic deformation scratch depth is given by

$$
b=\left(\frac{L_{\mathrm{N}} E^{\prime}}{H^{2}}\right)^{1 / 2}(\cot \phi)^{1 / 3}
$$

Here, $E^{\prime}$ is the relative modulus of elasticity and $\phi$ is the angle between opposite edges of the indenter. The depth of the radial cracks, gives the scratch depth for brittle fracture as follows:

$$
c=C_{\mathrm{R}}=\left[\xi_{\mathrm{r}}\left(\frac{E^{\prime}}{H}\right)^{1 / 2}\left(\frac{L_{\mathrm{N}}}{K_{\mathrm{Ic}}}\right)[\cot (\phi)]^{2 / 3}\right]^{2 / 3}
$$

where $\xi_{\mathrm{r}}$ is a dimensionless constant. There is a transition between plastic and brittle fracture scratching that takes place as the load is increased. Therefore, when the load on an impurity is less than $L_{\mathrm{Nc}}$ plastic deformation will take place; when the load on an impurity particle is greater than $L_{\mathrm{Nc}}$ brittle fracture will take place.

Particle impurities are forced by pad asperities to be in contact with the wafer surface. The asperities press the impurity particles into the wafer surface, creating a normal load that allows the depth of the surface damage to be predicted using Greenwood and Williamson's [82, 83] and Yu's theories [26]. Figure 35 shows the size distribution of scratches produced by the impurity particles. The deepest scratches were formed by the large impurity particles and the population of scratches decreased as the scratch depth increases for a given size of particle impurities.

Saka et al. [84] estimated the scratch formation at lower and upper-bound loads based on contact mechanics models. Additionally, the width and depth of scratches are dependent on process parameters such as particle size, abrasive volume fraction, and mechanical and geometric properties of the pad and surface coatings. In their study, interactions between the $\mathrm{Al}_{2} \mathrm{O}_{3}$ abrasive particles and the $\mathrm{Cu} /$ low $-k$ surface were described. They assumed that the Young's modulus and hardness of abrasive particles are greater than the coated films. Particles were assumed to be spherical and rigid with smooth and sufficiently thick. The radius of the contact on the coated film at yield 


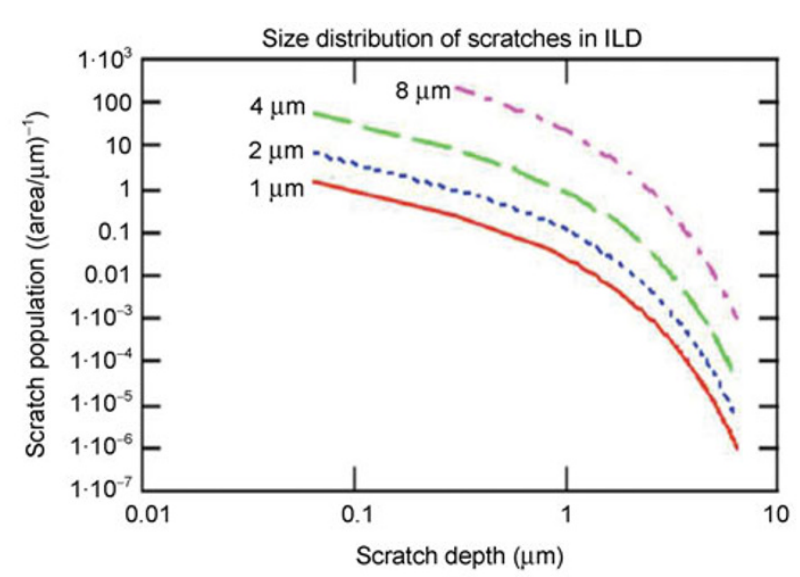

(a)

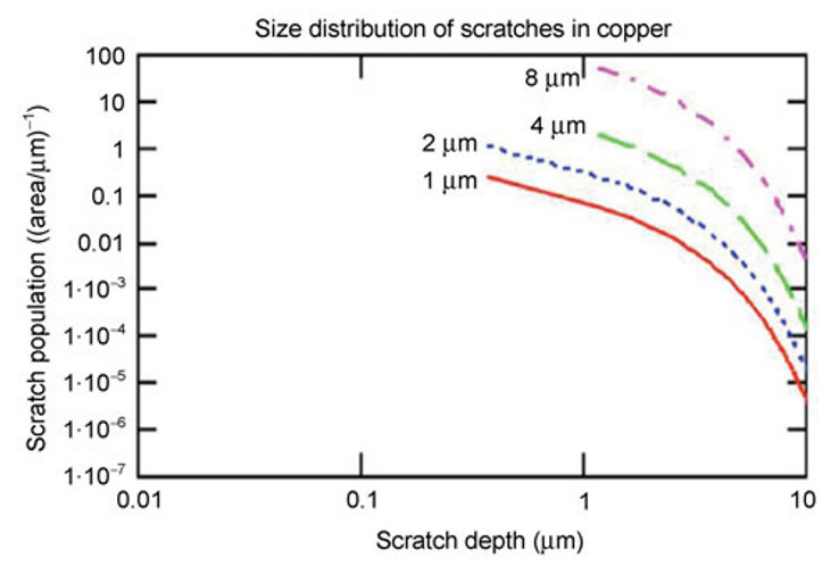

(b)

Fig. 35 Size distribution of scratches produced in (a) ILD and (b) copper by particle impurities (Reprinted with permission from Ref. [29]. Copyright 2007, The Electrochemical Society).

$\left(a_{Y, c}\right)$, the depth of the indentation in the film at yield load $\left(\delta_{Y, c}\right)$, the yield load $\left(P_{Y, c}\right)$ as a function of the particle radius $(R)$ and the mechanical properties of the coating were represented based on Hertzian analysis and the Tresca criterion for yielding as follows [84-86]:

$$
\begin{gathered}
a_{Y, \mathrm{c}}=\frac{\pi}{4} \frac{H_{\mathrm{c}}}{E_{\mathrm{c}}} R \\
\delta_{Y, \mathrm{c}}=\frac{\pi^{2}}{16} \frac{H_{\mathrm{c}}^{2}}{E_{\mathrm{c}}^{2}} R \\
P_{Y, \mathrm{c}}=\frac{\pi^{3}}{48} \frac{H_{\mathrm{c}}^{3}}{E_{\mathrm{c}}^{2}} R^{2}
\end{gathered}
$$

where $E_{\mathrm{c}}$ and $H_{\mathrm{c}}$ are the Young's modulus and hardness of the coated film, respectively. Figure 36 shows the geometry of the contact.

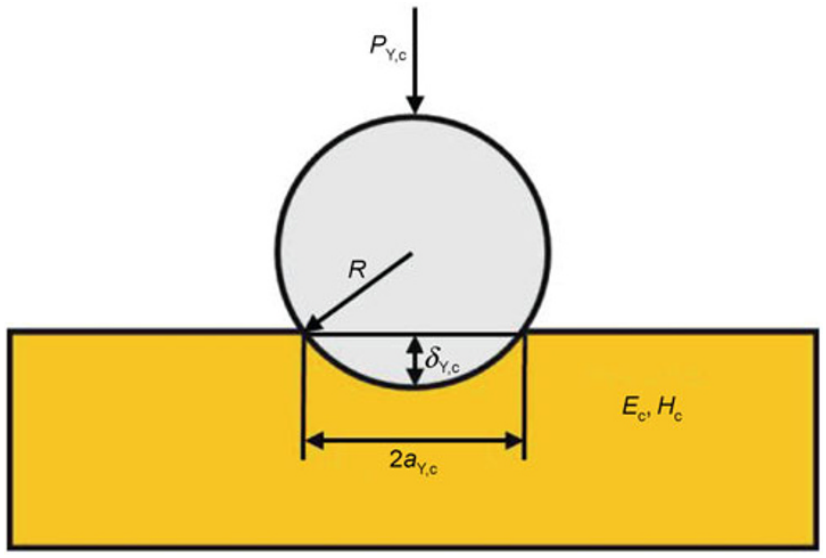

Fig. 36 Schematic of a hard particle indenting a soft coating at the onset of yielding [84].

During polishing under full-contact mode, abrasive particles sticking to the wafer were pressed, which is shown in Fig. 37. The hardness of coated film $\left(H_{c}\right)$ $[84,87]$, is given by

$$
H_{\mathrm{c}}=\frac{R_{\mathrm{UB}}}{A}=\frac{R_{\mathrm{UB}}}{\frac{\pi}{2} a_{\mathrm{c}}^{2}}
$$

where $P_{\mathrm{UB}}$ is the applied load, $A$ is the projected contact area, and $a_{\mathrm{c}}$ is the semi-width of a scratch. Based on the geometry of the scratch, the relation between the depth of the scratch $\left(\delta_{c}\right)$ and the semi-width is given by

$$
\frac{\delta_{\mathrm{c}}}{R}=\frac{1}{2}\left(\frac{a_{\mathrm{c}}}{R}\right)^{2} \quad\left(\delta_{\mathrm{c}}<a_{\mathrm{c}}\right)
$$

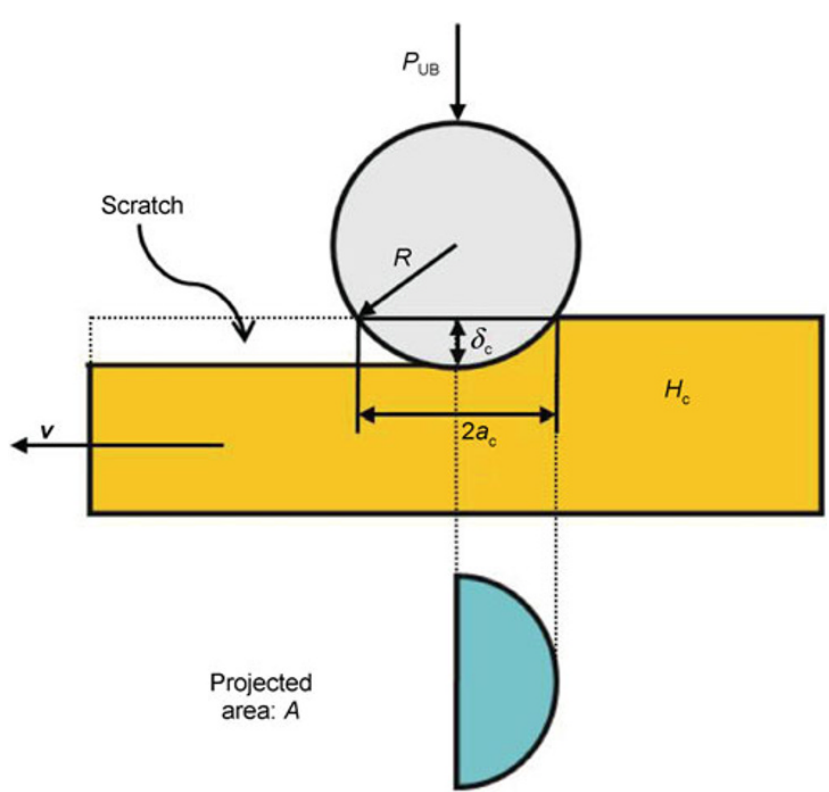

Fig. 37 A hard particle scratching a soft coating [84]. 
For a fully plastic contact, the semi-width and the depth of a scratch, and the upper-bound load, respectively, are

$$
\begin{gathered}
a_{\mathrm{c}}=\left[\frac{2 P_{\mathrm{UB}}}{\pi H_{\mathrm{c}}}\right]^{1 / 2} \\
\delta_{\mathrm{c}}=\frac{P_{\mathrm{UB}}}{\pi R H_{\mathrm{c}}} \\
P_{\mathrm{UB}}=\pi \delta_{\mathrm{c}} R H_{\mathrm{c}} \quad\left(\delta_{\mathrm{c}}<a_{\mathrm{c}} \ll R\right)
\end{gathered}
$$

Figure 38 shows the normalized experimental load versus the normalized scratch depth. The solid line represents the normalized upper-bound load. Therefore, all the points on the graph should be below the line of the upper bound load according to Eq. (18). In Fig. 38, all the points were below the solid line; therefore, the load per particle can be related to the scratch width and depth, according to Eq. (18). Based on the above modeling and experimental results, multi-particle contact behavior and the effect of pad asperity geometry for the initiation of scratches were analyzed [84, 88]. The various regimes of scratching by polishing pads in CMP have been delineated by contact mechanics based theoretical.

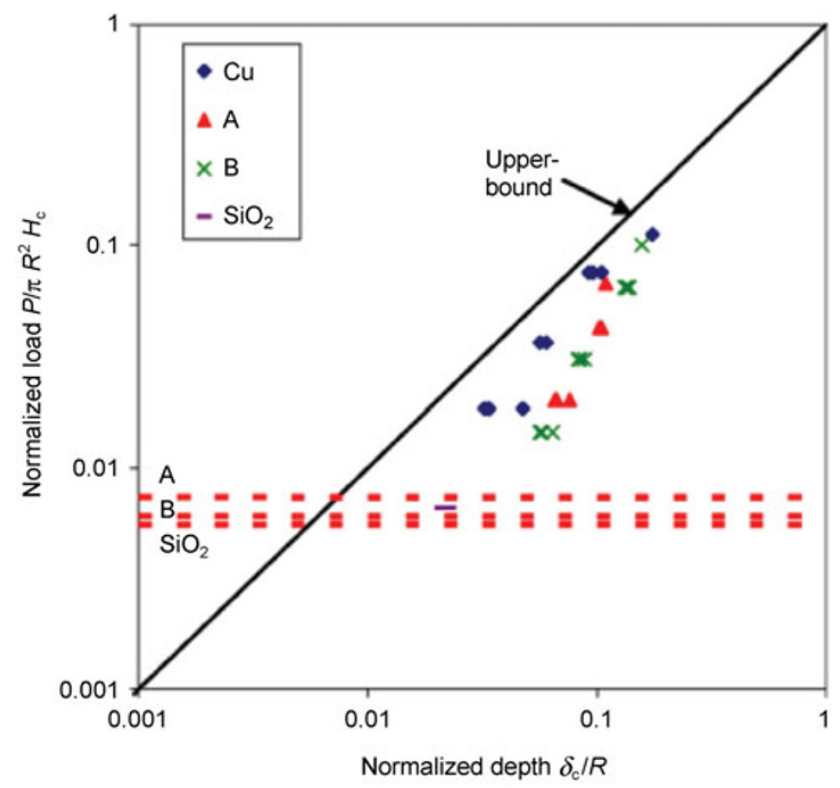

Fig. 38 Normalized experimental load versus the normalized scratch depth (Reproduced from Ref. [84], with permission from Elsevier).
Chandra et al. [89] proposed a multi-scale model encompassing the pad response and slurry behavior to predict the scratch propensity in CMP. The pad response delineates the interplay between the local particle-level deformation and the cell-level bending of the pad. Although the agglomeration process is traditionally classified into two separate regimes, diffusion-limited agglomeration (DLA) and reactionlimited agglomeration (RLA), DLA occurs near the iso-electric point of the slurry particles, while RLA occurs when the $\mathrm{pH}$ of the slurry is away from the iso-electric point [89]. For the general case, the agglomeration process can be modeled using the Smoluchowski rate equation $[89,90]$, which gives the time rate of change of the number of particle clusters with volume $M, N(M)$, as follows:

$$
\begin{aligned}
\frac{\mathrm{d}}{\mathrm{d} t} N(M)= & \frac{1}{2} \sum_{K=1}^{M-1} a(M, K) N(M-K) N(K) \\
& -\sum_{K=1}^{\infty} a(M, K) N(M) N(K)
\end{aligned}
$$

The agglomeration kernel, $a(M, K)$, is the rate at which clusters of volume $M$ agglomerate with particles of volume $K$. It has been shown that most agglomeration results from smaller particles sticking themselves onto a larger cluster [91]. The spatial distribution of the MRR is also affected by pad wear, which takes place mainly at the asperity level. The probability density function of the asperity height $z$ at any time $t$ is given as follows:

$$
\frac{\mathrm{d}}{\mathrm{d} t} \varphi(z, t)=\frac{4 C_{\mathrm{a}} E^{*} \sqrt{\kappa_{\mathrm{s}}}}{3 \pi} \frac{\partial}{\partial z}\{\sqrt{z-\mathrm{d}(t)} \varphi(z, t)\}
$$

where $C_{a}$ is the pad wear rate coefficient, $E^{*}$ is the effective modulus of the pad and $\kappa_{\mathrm{s}}$ is pad asperity tip curvature. Also, the calculation of scratch depth involves two random variables, pad asperity height $(z)$ and effective particle cluster radius $(X)$. The two variables are independent and the scratch depth $W(i, j)$ due to the $j^{\text {th }}$ particle under the $i^{\text {th }}$ asperity is given by $[89,91]$

$$
W(i, j)=\frac{E^{*} \sqrt{\kappa_{\mathrm{s}}}}{H \pi} \sqrt{z-\mathrm{d}(t)} X(i, j)
$$

Using the above equations, the cumulative density function of the scratch depth can be calculated. The 
probability per active particle, $P(W \leqslant \omega)$, a scratch of depth $W$, which is less than a prescribed threshold $\omega$, will be created and is given by

$$
P(W \leqslant w)=\int_{0}^{X_{\max }} \int_{0}^{w^{2} / H^{2}} f_{z^{\prime}}(z) f_{x}(x) \mathrm{d} z^{\prime} \mathrm{d} x
$$

The model predictions were compared with the experimental results in Fig. 39. The maximum scratch depth predicted by the model was much lower. This discrepancy was thought to be caused by inaccuracies in the assumed initial particle distribution in the slurry. This might be due to the contamination of the slurry with a very low percentage of relatively large particles.

Additionally, the model was adopted as a function of pad modulus and wafer surface hardness. The scratch depth was affected by pad modulus, and hence

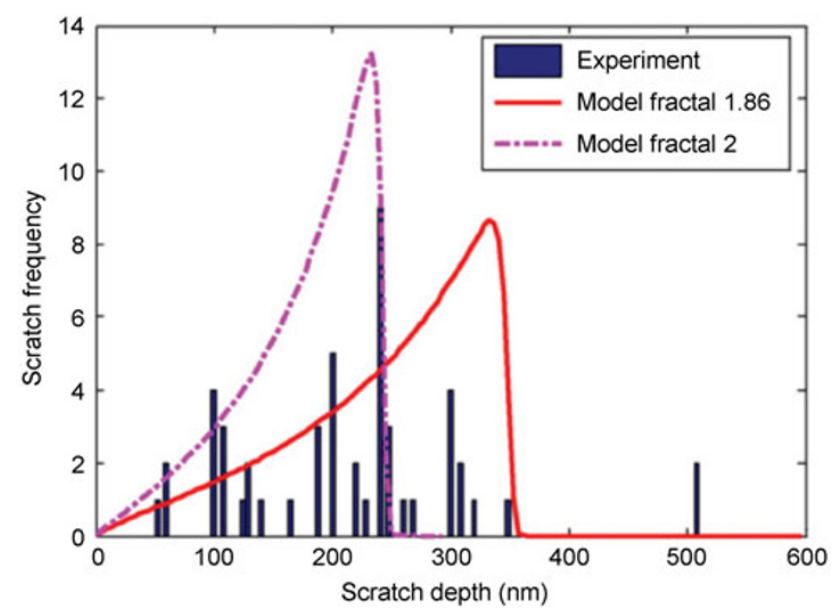

Fig. 39 Normalized experimental load versus the normalized scratch depth (Reproduced from Ref. [89], with permission from Elsevier). the probability density of scratch depth, which was simulated from the proposed equations. It was observed that the scratch depth increased while scratch frequency decreased for harder pads as well as for softer wafer surfaces.

Typically, chatter mark-type scratches, which have a repetitive C-shaped crack, were generated in interlevel dielectric (ILD) materials (Fig. 40). In this image, the cracks are larger at one end and smaller at the other end of the repetitive line. Furthermore, the repetitive C-shaped surface showed damage that is tens of $\mathrm{nm}$ deep with some individual cracks that were deeper than others, in atomic force microscope (AFM) images. Ring et al. [29] explained this phenomenon based on bouncing particle model. The springiness of the pad causes the particle to bounce against the wafer surface. Bouncing may be initiated by a particle impurity that is sliding across the surface of the wafer. After the first bounce, the particles have sufficient force to indent the surface of the wafer. This force is supplied by the elastic properties of the pad when the particle is pushed into it and then rebounds. The frequency of bounces can be determined by the simple physics of a mass (the particle) on a spring (the pad). The governing equation is given by

$$
F=k_{1} x=m \frac{\mathrm{d}^{2} x}{\mathrm{~d} t^{2}}
$$

where $F$ is the force supplied by elastic property of the pad, $k_{1}$ is the spring constant of the pad, $m$ is the mass of the particle and $x$ is the vertical distance that the particle moves into the pad during rebound. The
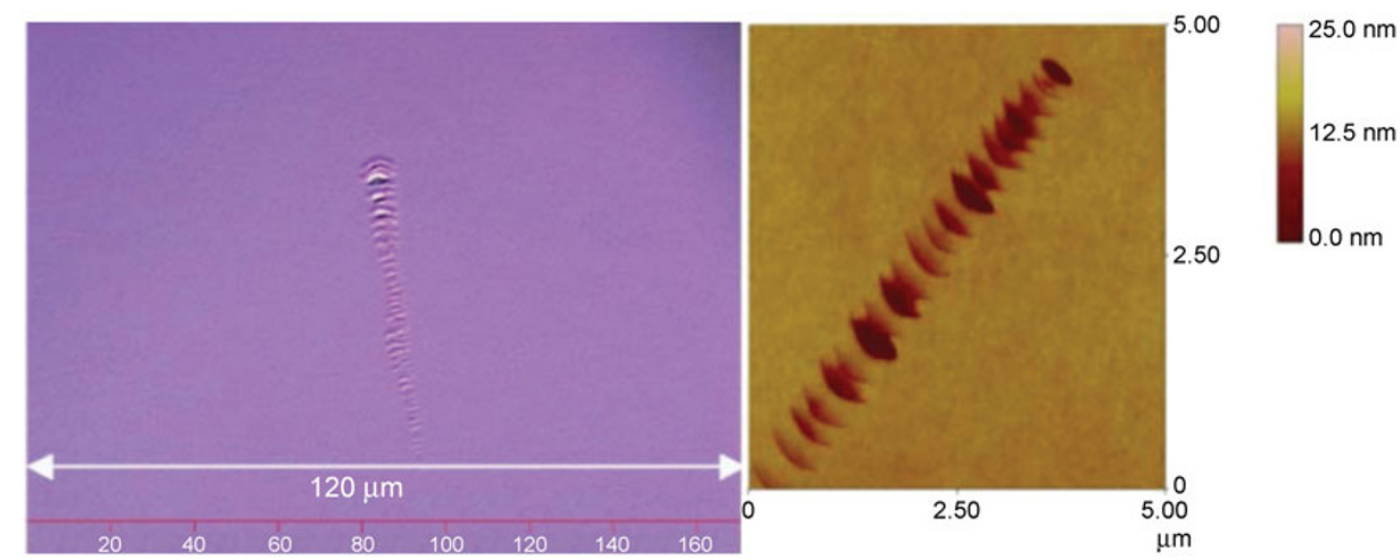

Fig. 40 Chatter surface damage showing repetitive, 40-nm-deep indentations in the wafer surface (Reprinted with permission from Ref. [29]. Copyright 2007, The Electrochemical Society). 
solution to the above equation is given by

$$
x=A \sin \left(\omega t+\theta_{0}\right)
$$

where $A$ is the amplitude, which is given by

$$
A=\sqrt{x_{0}^{2}+\left(\frac{v_{0}}{\omega}\right)^{2}}
$$

where $x_{0}$ is the initial displacement of the particle in the pad and $v_{0}$ is the initial vertical velocity of the particle. The angular frequency, $\omega$ (and frequency, $f$ ) for a mass on a spring are given by

$$
\omega=\frac{2 \pi}{T}=2 \pi f=\sqrt{\frac{k_{1}}{m}}
$$

where $T$ is the period of oscillation.

During the oxide CMP, even more chatter marktype scratches are formed on the wafer surface [90]. However, the explanation of chatter mark scratch generation using only basic contact theory is not easy. Stick-slip phenomena between two sliding surfaces are commonly observed in a wide range of length scales from atomic to macroscopic [73, 91, 92]. Gao et al. $[92,93]$ developed an empirical equation describing the stick-slip friction as a function of humidity, speed, and applied load. Zhang and Li [94] proposed that the normal load is the main contributing factor in the scratch force, rather than the driving speed during stick-slip, and proposed a micromechanical model to describe the slip process. Figure 41 shows a simple model of that proposed scratch system. The effective

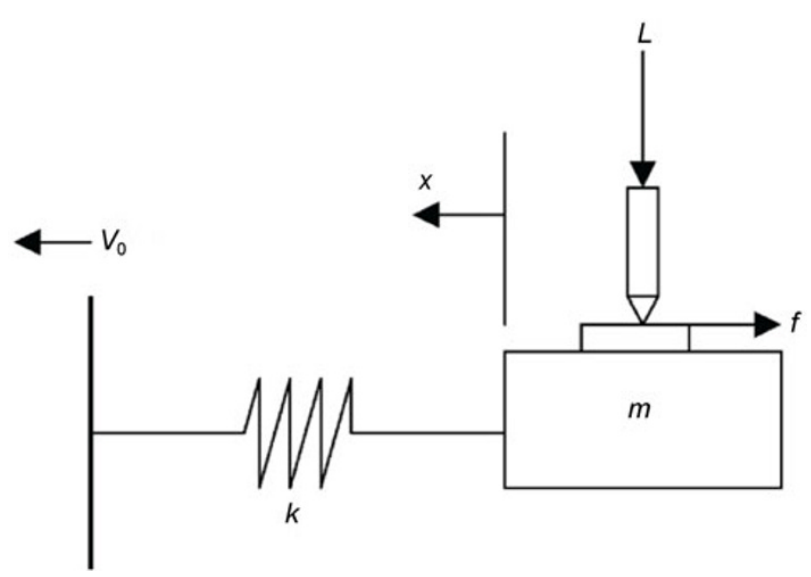

Fig. 41 A simple model of the scratch system (Reproduced from Ref. [94], with permission from Elsevier). spring constant $k$ of the model connecting the step motor (moving at a constant speed $V_{0}$ ) to the slider can be obtained from the slope of the horizontal force versus time curve (Fig. 42) during the sticking stage. The total mass of the slider and sample is $m$. $L$ is the normal load applied to the specimen and $x$ is the real scratch distance moved by the indenter. The force balance in the sliding direction is given by

$$
k\left(V_{0} t-x\right)-f=m \ddot{x}
$$

During scratching, the horizontal force is measured by $k\left(V_{0} t-x\right)$, where $k\left(V_{0} t-x\right)$ is the real extension of the spring being stretched, $f$ is the force needed to plastically deform the material in front of the indenter. A saw-tooth wave form characteristic of stick-slip behavior is shown in Fig. 42. It was observed that the scratching motion was preceded by jerks instead of a smooth path. In their result, it was reported that, during slip, the indenter velocity started from zero, increased to a maximum and then decreased to zero again. The scratch groove made during slip showed a non-uniform depth, which increased with decreasing of scratch velocity. Although the scratch velocity and groove depth changed markedly during slip stage, the scratch force remained almost constant for most of the scratch distance.

Kim et al. [95] also studied the generation of chatter mark scratches and proposed the controlling parameters for chatter mark scratching. Based on the force balance in the sliding direction, stick-slip friction was used in the model. The distance between chatter marks

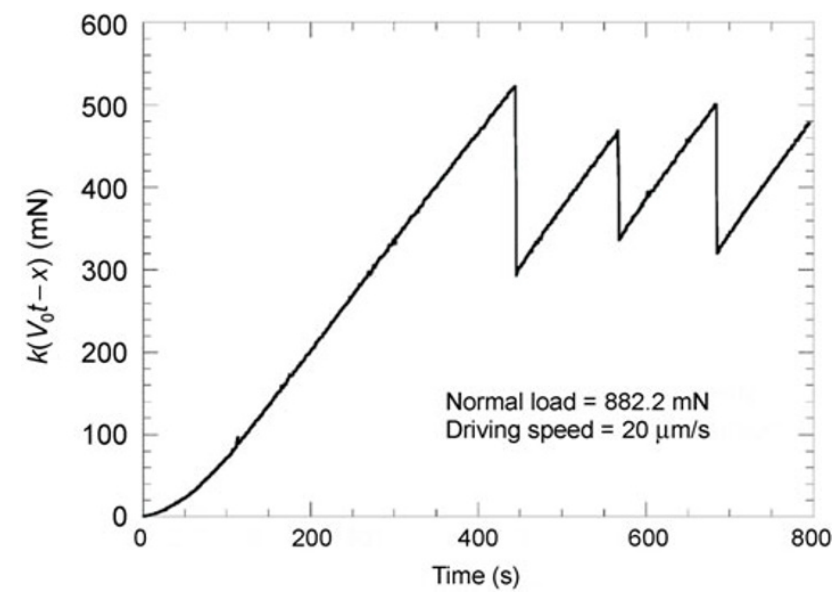

Fig. 42 The horizontal force measured by the load cell, $k\left(V_{0} t-x\right)$ (Reproduced from Ref. [94], with permission from Elsevier). 
was predicted by controlling the applied velocity to characterize the chatter scratch formation. Thus, the particle position from the starting point increased with increased oscillatory motion and sliding time (or distance).

\section{Concluding Remarks}

CMP is a unique technology in the fabrication of semiconductor devices. Also, CMP is very important in achieving the uniform global planarity without any defects. Several models were introduced to understand the material removal rate based on the Preston equation. However, several defects, such as particle adhesion, deposition of slurry residue, scratching, and pitting, occur on the surface. Among these, the most detrimental defects were found to be scratches, as these directly affect the yield and potential reliability of the devices. In this review, various scratch detection methods as well as sources of scratch formation were described in detail. Typically, scratches are generated by byproducts such as large particles and agglomerated particles in a slurry, and pad debris with abrasion between the wafer and pad in the slurry. Filtration was introduced to reduce or to control the large particles and agglomerated particles in the slurry. Additionally, the effect of abrasive particle type, size, hardness and surface modification methods were discussed. Particle agglomeration behavior during slurry circulation in the slurry supply system and its effect on scratch formation were discussed. The polishing pad is a main consumable in the CMP process. The effect of pad groove and pores for MRR and scratch formation was explained and new pads were introduced with various diamond conditioner types. As a result of pad conditioning, pad debris can be generated, which is adsorbed with the abrasive particles, and can therefore also act as a scratch generation source. Lastly, the scratch formation mechanism and experimental results based on basic contact theory and fracture mechanisms were discussed, and the particle bouncing model and stick-slip models for chatter mark scratch formation, the main scratch type, were reviewed.

Open Access: This article is distributed under the terms of the Creative Commons Attribution License which permits any use, distribution, and reproduction in any medium, provided the original author(s) and source are credited.

\section{References}

[1] Zantye P B, Kumar A, Sikder A K. Chemical mechanical planarization for microelectronics applications. Mater Sci Eng R Rep 45(3-6): 89-220 (2004)

[2] DeJulie R. CMP grows in sophistication. Semiconductor International 21(13): 56-80 (1998)

[3] Oliver M R. Chemical-Mechanical Planarization of Semiconductor Materials. Berlin (Germany): Springer, 2004.

[4] Fury M A. The early days of CMP. Solid State Technol 40: 81 (1997)

[5] Steigerwald J M, Murarka S P, Gutmann R J. Chemical Mechanical Planarization of Microelectronic Materials. New York (USA): John Wiley \& Sons, 1997.

[6] Ali I, Roy S R, Shinn G. Chemical mechanical polishing of interlayer dielectric: A review. Solid State Technol 10: 63-70 (1994)

[7] Li Y. Microelectronic Applications of Chemical Mechanical Planarization. New Jersey (USA): John Wiley Sons, 2007.

[8] Liang H, Kaufman F, Sevilla R, Anjur S. Wear phenomena in chemical mechanical polishing. Wear 211(2): 271-279 (1997)

[9] Palla B J, Shah D O. Correlation of observed stability and polishing performance to abrasive particle size for CMP. In Proceedings of the IEEE/CPMT International Electronics Manufacturing Technology (IEMT) Symposium, 1999: 362369.

[10] Luo J, Dornfeld D A. Effects of abrasive size distribution in chemical mechanical planarization: Modeling and verification. IEEE T Semiconduct M 16(3): 469-476 (2003)

[11] Gokhale K S, Moudgil B M. Particle technology in chemical mechanical planarization. KONA 25: 88-96 (2007)

[12] Zhao B, Shi F G. Chemical mechanical polishing: Threshold pressure and mechanism. Electrochem Solid-State Lett 2(3): 145-147 (1999)

[13] Basim G B, Adler J J, Mahajan U, Singh R K, Moudgil B M. Effect of particle size of chemical mechanical polishing slurries for enhanced polishing with minimal defects. $J$ Electrochem Soc 147(9): 3523-3528 (2000)

[14] Inaba S, Katsuyama T, Tanaka M. Study of CMP polishing pad control method. In 1998 Proceedings of the Third International Chemical-Mechanical Planarization for VLSI Multilevel Interconnection Conference (CMP-MIC), 1998: 44-51. 
[15] Jairath R, Desai M, Stell M, Telles R, Scherber-Brewer D. Consumables for the chemical mechanical polishing (CMP) of dielectrics and conductors. In Materials Research Society Symposium - Proceedings, 1994: 121-131.

[16] Yamada Y, Kawakubo M, Hirai O, Konishi N, Kurokawa S, Doi T. Frictional characterization of chemical-mechanical polishing pad surface and diamond conditioner wear. Jpn $J$ Appl Phys Part 1 47(8): 6282-6287 (2008)

[17] Preston F W. The theory and design of plate lass polishing machines. J Soc Glass Tech 11: 214-256 (1927)

[18] Luo Q, Ramarajan S, Babu S V. Modification of the Preston equation for the chemical mechanical polishing of copper. Thin Solid Films 335(1-2): 160-167 (1998)

[19] Cook L M. Chemical processes in glass polishing. J Noncryst Solids 120: 152-171 (1990)

[20] Liu C W, Dai B T, Tseng W T, Yeh C F. Modeling of the wear mechanism during chemical-mechanical polishing. Journal of the Electrochemical Society 143(2): 716-721 (1996)

[21] Runnels S R. Feature-scale fluid-based erosion modeling for chemical mechanical polishing. J Electrochem Soc 141(7): 1900-1904 (1994)

[22] Tseng W T, Wang T L. Re-examination of pressure and speed dependence of removal rate during chemical mechanical polishing processes. J Electrochem Soc 144(2): L15-L17 (1997)

[23] Zhang F, Busnaina A A, Ahmadi G. Particle adhesion and removal in chemical mechanical polishing and post-CMP cleaning. J Electrochem Soc 146(7): 2665-2669 (1999)

[24] Ahmadi G, Xia X. A model for mechanical wear and abrasive particle adhesion during the chemical mechanical polishing process. J Electrochem Soc 148(3): G99-G109 (2001)

[25] Park K H, Kim H J, Chang O M, Jeong H D. Effects of pad properties on material removal in chemical mechanical polishing. J Mater Process Tech 187-188: 73-76 (2007)

[26] Yu T K, Yu C C, Orlowski M. Statistical polishing pad model for chemical-mechanical polishing. In Electron Devices Meeting 1993. IEDM'93. Technical Digest, International. IEEE, 1993: 865-868.

[27] Zhao B, Shi F G. Chemical mechanical polishing in IC processes: New fundamental insights. In Proceedings of the Fourth International Chemical Mechanical Planarization for ULSI Multilevel Interconnection Conference, 1999: 12-22.

[28] Luo J, Dornfeld D A. Material removal mechanism in chemical mechanical polishing: theory and modeling. IEEE T Semiconduct M 14(2): 112-133 (2001)

[29] Ring T A, Feeney P, Boldridge D, Kasthurirangan J, Li S, Dirksen J A. Brittle and ductile fracture mechanics analysis of surface damage caused during CMP. J Electrochem Soc
154(3): H239-H248 (2007)

[30] Seo Y J, Kim S Y, Lee W S. Reduction of process defects using a modified set-up for chemical mechanical polishing equipment. Microelectron Eng 65(4): 371-379 (2003)

[31] Lee S I, Hwang J, Kim, Jeong H. Investigation of polishing characteristics of shallow trench isolation chemical mechanical planarization with different types of slurries. Microelectron Eng 84(4): 626-630 (2007)

[32] Yamada Y, Konishi N, Noguchi J, Jimbo T. Influence of CMP slurries and post-CMP cleaning solutions on $\mathrm{Cu}$ interconnects and TDDB reliability. $J$ Electrochem Soc 155(7): H485-H490 (2008)

[33] Krishnan M, Nalaskowski J W, Cook L M. Chemical mechanical planarization: Slurry chemistry, materials, and mechanisms. Chem Rev 110(1): 178-204 (2010)

[34] Jung S M, Uom J S, Cho W S, Bae Y J, Chung Y K, Yu K S, Kim K Y, Kim K. A study of formation and failure mechanism of CMP scratch induced defects on ILD in a W-damascene interconnect SRAM cell. In Reliability Physics Symposium, 2001. Proceedings. 39th Annual. 2001 IEEE International. IEEE, 2001: 42-47.

[35] Kim H J, Yang J C, Yoon B U, Lee H D, Kim T. Nanoscale stick-slip friction model for the chatter scratch generated by chemical mechanical polishing process. J Nanosci Nanotech 12(7): 5683-5686 (2012)

[36] International technology roadmap for semiconductors, http://www.itrs.net/, 2010.

[37] Ding P, Starr G W, Chowdhury P, Hirleman E D. Defect characterization and light scattering by PSL spheres on tungsten CMP wafers. In Proc. SPIE 3215, In-Line Characterization Techniques for Performance and Yield Enhancement in Microelectronic Manufacturing, Austin, USA, 1997: 50-60.

[38] McGarvey S, Miller A E. Surface scanning inspection system defect classification of CMP induced scratches. In Proc. SPIE 7971, Metrology, Inspection, and Process Control for Microlithography XXV, San Jose, California, USA, 2011: 79712P1-8.

[39] Abbadie A, Cresente F, Séméria M N. Advanced wet cleaning post-CMP. Application to reclaim wafers. $J$ Electrochem Soc 151(1): G57-G66 (2004)

[40] Kim S Y, Park S W, Seo Y J. Improvements of CMP characteristics using slurry filter and high-spray bar of deionized water. J Mater Sci-Mater El 13(12): 693-696 (2002)

[41] Kasai T, Dowell C, Somanchi A. Application of a laser assisted defect detection system for chemical mechanical planarization slurry development in rigid disk polishing. Meas Sci Technol 18(5): 1582-1590 (2007)

[42] Stokowski S, Vaez-Iravani M. Wafer inspection technology 
challenges for ULSI manufacturing. In AIP Conference Proceedings, Gaithersburg, Maryland, USA, 1998: 405.

[43] Seo Y J, Kim S Y, Lee W S. Advantages of point of use (POU) slurry filter and high spray method for reduction of CMP process defects. Microelectron Eng 70: 1-6 (2003)

[44] Teo T Y, Goh W L, Leong L S, Lim V S K, Tse T Y, Chan L. Characterization and reduction of copper chemical mechanical polishing induced scratches. In Proc. SPIE 5041, Process and Materials Characterization and Diagnostics in IC Manufacturing, Santa Clara, CA, USA, 2003: 61-69.

[45] Ahn Y, Yoon J Y, Baek C W, Kim Y K. Chemical mechanical polishing by colloidal silica-based slurry for micro-scratch reduction. Wear 257(7-8): 785-789 (2004)

[46] Kim D H, Kang H G, Kim S K, Paik U, Park J G. Agglomerated large particles under various slurry preparation conditions and their influence on shallow trench isolation chemical mechanical polishing. Jpn J Appl Phys Part 1 44(11): 7770-7776 (2005)

[47] Remsen E E, Anjur S, Boldridge D, Kamiti M, Li S, Johns T, Dowell C, Kasthurirangan J, Feeney P. Analysis of large particle count in fumed silica slurries and Its Correlation with scratch defects generated by CMP. J Electrochem Soc 153(5): G453-G461 (2006)

[48] Coutinho C A, Mudhivarthi S R, Kumar A, Gupta V K. Novel ceria-polymer microcomposites for chemical mechanical polishing. Appl Surf Sci 255(5 Part 2): 3090-3096 (2008)

[49] Jindal A, Hegde S, Babu S V. Chemical mechanical polishing using mixed abrasive slurries. Electrochem Solid-State Lett 5(7): G48-G50 (2002)

[50] Wrschka P, Hernandez J, Oehrlein G S, Negrych J A, Haag G, Rau P, Currie J E. Development of a slurry employing a unique silica abrasive for the CMP of $\mathrm{Cu}$ damascene structures. J Electrochem Soc 148(6): G321-G325 (2001)

[51] Lei H, Zhang P. Preparation of alumina/silica core-shell abrasives and their CMP behavior. Appl Surf Sci 253(21): 8754-8761 (2007)

[52] Armini S, Whelan C M, Maex K, Hernandez J L, Moinpour M. Composite polymer-core silica-shell abrasive particles during oxide CMP: A defectivity study. J Electrochem Soc 154(8): H667-H671 (2007)

[53] Armini S, Burtovyy R, Moinpour M, Luzinov I, De Messemaeker J, Whelan C M, Maex K. Interaction forces between a glass surface and ceria modified PMMA based abrasives for CMP measured by colloidal probe AFM. $J$ Electrochem Soc 155(4): H218-H223 (2008)

[54] Armini S, Whelan C M, Moinpour M, Maex K. Composite polymer core-silica shell abrasives: The effect of the shape of the silica particles on oxide CMP. J Electrochem Soc 155(6): H401-H406 (2008)
[55] Chang F C, Tanawade S, Singh R K. Effects of stress-induced particle agglomeration on defectivity during CMP of low- $k$ dielectrics. J Electrochem Soc 156(1): H39-H42 (2009)

[56] Yi C, Tsai C F, Wang J F. Stabilization of slurry used in chemical mechanical polishing of semiconductor wafers by adjustment of $\mathrm{pH}$ of deionized water. U.S. Patent 6130 163, Oct. 2000.

[57] Chang F C, Singh R K. Method for quantifying the degree of agglomeration in highly stable chemical mechanical polishing slurries. Electrochem Solid-State Lett 12(4): H127-H130 (2009)

[58] Donis R, Fisher M, Bauck L. Effect of slurry distribution using diaphragm and centrifugal pupms on the defectivity in a Cu CMP process. ECS Trans 25(38): 47-54 (2010)

[59] Hooper B J, Byrne G, Galligan S. Pad conditioning in chemical mechanical polishing. J Mater Process Tech 123(1): 107-113 (2002)

[60] Landis H, Burke P, Cote W, Hill W, Hoffman C, Kaanta C, Koburger C, Lange W, Leach M, Luce S. Integration of chemical-mechanical polishing into CMOS integrated circuit manufacturing. Thin Solid Films 220(1-2): 1-7 (1992)

[61] Lee W J, Park H S, Shin H C. Enhancement of CMP pad lifetime for shallow trench isolation process using profile simulation. Curr Appl Phys 9(1): S134-S137 (2009)

[62] Choi J G, Prasad Y N, Kim I K, Kim W J, Park J G. The synergetic role of pores and grooves of the pad on the scratch formation during STI CMP. $J$ Electrochem Soc 157(8): H806-H809 (2010)

[63] Wang Y C, Yang T S. Effects of pad grooves on chemical mechanical planarization. J Electrochem Soc 154(6): H486H494 (2007)

[64] Thakurta D G, Borst C L, Schwendeman D W, Gutmann R J, Gill W N. Pad porosity, compressibility and slurry delivery effects in chemical-mechanical planarization: Modeling and experiments. Thin Solid Films 366(1-2): 181-190 (2000)

[65] Rosales-Yeomans D, Doi T, Kinoshita M, Suzuki T, Philipossian A. Effect of pad groove designs on the frictional and removal rate characteristics of ILD CMP. J Electrochem Soc 152(1): G62-G67 (2005)

[66] Hsien Y H, Hsu H K, Tsai T C, Lin W, Huang R P, Chen C H, Yang C L, Wu J Y. Process development of high-k metal gate aluminum CMP at $28 \mathrm{~nm}$ technology node. Microelectron Eng 92: 19-23 (2012)

[67] Choi J G, Prasad Y N, Kim I K, Kim I G, Kim W J, Busnaina A A, Park J G. Analysis of scratches formed on oxide surface during chemical mechanical planarization. $J$ Electrochem Soc 157(2): H186-H191 (2010)

[68] Eusner T, Saka N, Chun J H. Breaking-in a pad for scratch-free, $\mathrm{Cu}$ chemical-mechanical polishing. J Electrochem 
Soc 158(4): H379-H389 (2011)

[69] Tsai M Y, Chen W K. Effect of CMP conditioner diamond shape on pad topography and oxide wafer performances. Int $J$ Adv Manuf Tech 55(1-4): 253-262 (2011)

[70] Yang J C, Choi J H, Hwang, Lee C G, Kim T. Effects of diamond size of CMP conditioner on wafer removal rates and defects for solid (non-porous) CMP pad with micro-holes. Int J Mach Tool Manu 50(10): 860-868 (2010)

[71] Yang J C, Kim H, Lee C G, Lee H D, Kim T. Optimization of CMP pad surface by laser induced micro hole. $J$ Electrochem Soc 158(1): H15-H20 (2011)

[72] Prasad Y N, Kwon T Y, Kim I K, Kim I G, Park J G. Generation of Pad debris during oxide CMP process and Its role in scratch formation. $J$ Electrochem Soc 158(4): H394-H400 (2011)

[73] Kwon T Y, Cho B J, Ramachandran M, Busnaina A A, Park J G. Investigation of Source-Based Scratch Formation During Oxide Chemical Mechanical Planarization. Tribol Lett 50(2): 169-175 (2013)

[74] Yang J C, Oh D W, Kim H J, Kim T. Investigation on surface hardening of polyurethane pads during chemical mechanical polishing (CMP). J Electron Mater 39(3): 338-346 (2010)

[75] Lin M, Chang C Y, Liao D C, Wang B, Henderson A. Improved STI CMP technology for micro-scratch issue. In Proceedings of Chemical Mechanical Polishing-Multilevel Interconnection Conference, Santa Clara, 1999: 322.

[76] Huang J, Chen H C, Wu J Y, Lur W. Investigation of CMP micro-scratch in the fabrication of sub-quarter micron VLSI circuit. In Proceedings of Chemical Mechanical PolishingMultilevel Interconnection Conference, Santa Clara, 1999: 77-79.

[77] Benner S J, Perez G, Peters D W, Hue K, O'Hagan P. Reduction of CMP-induced wafer defects through in-situ removal of process debris. In Advanced Semiconductor Manufacturing Conference (ASMC), 2011 22nd Annual IEEE/SEMI. IEEE, 2011: 1-4.

[78] Suratwala T, Wong L, Miller P, Feit M D, Menapace J, Steele R, Davis P, Walmer D. Sub-surface mechanical damage distributions during grinding of fused silica. $J$ Non-cryst Solids 352(52-54): 5601-5617 (2006)

[79] Lawn B. Fracture of Brittle Solids. New York (USA): Cambridge university press, 1993.

[80] Hutchings I M. Tribology: Friction and Wear of Engineering
Materials. London (UK): Butterworth-Heinemann Ltd., 1992.

[81] Suratwala T, Steele R, Feit M D, Wong L, Miller P, Menapace J, Davis P. Effect of rogue particles on the subsurface damage of fused silica during grinding/polishing. J Non-cryst Solids 354(18): 2023-2037 (2008)

[82] Greenwood J A. The area of contact between rough surfaces and flats. J Lubr Technol Trans ASME 89: 81 (1967)

[83] Greenwood J A, Williamson J B P. Contact of nominally flat surfaces. Proc R Soc Lond A 295(1442): 300-319 (1966)

[84] Saka N, Eusner T, Chun J H. Nano-scale scratching in chemical-mechanical polishing. CIRP Ann Manuf Technol 57(1): 341-344 (2008)

[85] Johnson K L. Contact Mechanics. New York (USA): Cambridge university press, 1987.

[86] Suh N P. Tribophysics. New Jersey (USA): Prentice-Hall, Englewood Cliffs, 1986.

[87] Maugis D, Pollock H M. Surface forces, deformation and adherence at metal microcontacts. ACTA Metall 32(9): 1323-1334 (1984)

[88] Saka N, Eusner T, Chun J H. Scratching by pad asperities in chemical-mechanical polishing. CIRP Ann Manuf Technol 59(1): 329-332 (2010)

[89] Chandra A, Karra P, Bastawros A F, Biswas R, Sherman P J, Armini S, Lucca D A. Prediction of scratch generation in chemical mechanical planarization. CIRP Ann Manuf Technol 57(1): 559-562 (2008)

[90] Ball R C, Weitz D A, Witten T A, Leyvraz F. Universal kinetics in reaction-limited aggregation. Phys Rev Lett 58(3): 274-277 (1987)

[91] Che W, Guo Y, Chandra A, Bastawros A. A scratch intersection model of material removal during chemical mechanical planarization (CMP). J Manuf Sci Eng 127(3): 545-554 (2005)

[92] Gao C, Kuhlmann-Wilsdorf D, Makel D D. Fundamentals of stick-slip. Wear 162-164(PART B): 1139-1149 (1993)

[93] Gao C, Kuhlmann-Wilsdorf D, Makel D D. The dynamic analysis of stick-slip motion. Wear 173(1-2): 1-12 (1994)

[94] Zhang S L, Li J C M. Slip process of stick-slip motion in the scratching of a polymer. Mater Sci Eng A 344(1-2): 182-189 (2003)

[95] Kim H J, Yang J C, Yoon B U, Lee H D, Kim T. Nano-scale stick-slip friction model for the chatter scratch generated by chemical mechanical polishing process. $J$ Nanosci Nanotech 12(7): 5683-5686 (2012) 


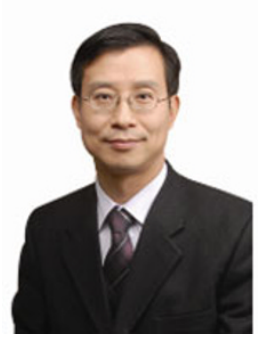

Jin-Goo PARK. He received $\mathrm{PhD}$ degree in materials science and engineering from University of Arizona in 1993. From 1992 to 1994, he was with Texas Instruments, Dallas, TX, where he was responsible for microcontamination control in semiconductor wet processing and DMD development. In 1994, he joined Hanyang University at Ansan, where he is now a professor in the Department of Materials Engineering as well as

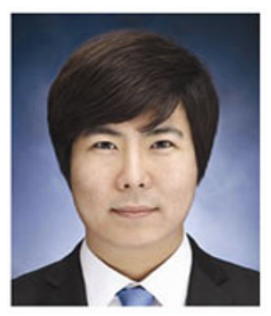

Tae-Young KWON. He received his Bachelor degree in Department of Materials Engineering in 2006 from Hanyang University, Ansan, Korea. After then, he was a M.S. directors of Micro Biochip Center and Nano-bio Electronic Materials and Processing Lab. (NEMPL, www.nempl.net). His research interests include wafer cleanings and chemical mechanical polishing as well as nano-bio MEMS. He is now president of Korea CMPUGM (www.cmpugm.com) and a founder and president of International Conference on Planarization/CMP Technology (ICPT) which is the largest CMP conference in the world. He is also a founder of Korea Surface Cleaning Users Group Meeting (www.scugm.com).

and Ph.D. student at the same university. He has recently obtained his Ph.D. degree in Department of Materials Engineering at Hanyang University. His research interests include Chemical Mechanical Planarization process and its tribology. 